\title{
Can Shocks to Risk Aversion Explain Business Cycle Fluctuations in Bulgaria (1999-2019)?
}

\author{
Aleksandar Vasilev \\ Lincoln International Business School, UK \\ avasilev@lincoln.ac.uk
}

\begin{abstract}
Stochastic risk aversion is introduced into a dynamic general-equilibrium setup augmented with government. The theoretical framework is calibrated to Bulgarian data for the period 1999-2019. The quantitative relevance of shocks to risk aversion is investigated for the propagation of business cycles in the Bulgarian economy. More specifically, the presence of stochastic risk aversion in the theoretical setup improves the fit vis-à-vis data by increasing variability of employment and decreasing the variability of investment. However, those improvements are at the expense of lowering the variability of investment and wages in the model economy.

Key Words: business cycles, stochastic risk aversion, Bulgaria

JEL Classification: E24, E32

(cc)BY-SA https://doi.org/10.26493/1854-6935.19.271-284
\end{abstract}

\section{Introduction and Motivation}

The classical real-business-cycle (R B C) model, e.g. Hansen (1985), revolutionized modern quantitative dynamic macroeconomics as it was a unique modelling tool that allowed researchers to construct artificial model economies, which resemble those of existing countries along important aggregate dimensions, and use those simulated environments to generate artificial, or model-predicted data, which is then compared to the properties of empirical (observed) data. In this way, all dynamic general-equilibrium frameworks could be regarded as disciplined datagenerating mechanisms for data matching akin to the general method of moments (GMM) in econometrics. Alternatively, those simulated data series could be interpreted as a maximum likelihood estimation (MLE), investigating how likely it is that the observed time series were produced by the theoretical model. In addition, and in important contrast to ad hoc dynamic econometric models (e.g. Vector-Auto-Regressions, or VARs) used in time series analysis, the important transmission mechanisms 
(based on inter- and intra-temporal optimality principles) in these theoretical model economies are explicit, as those setups are based on microfoundations, so macroeconomists could gain a deeper understanding of the intricacies of the real economies. Finally, those model economies could be used as a laboratory, where different computational experiments can be safely executed, and which could produce quantitative insights about the expected and unexpected effects of policies and reforms that are still in a proposal stage. ${ }^{1}$

The general approach used in quantitative theoretical macroeconomic papers to set the values of the model parameters is referred to as calibration. In contrast to what many applied researchers wrongfully think or believe, calibration (when executed correctly) is not arbitrary at all; in particular, calibration is preferred to estimation in cases when (i) time series are too short to allow for a sensible estimation; (ii) when we already have data for certain parameters, like the depreciation rate, or the labour and capital shares; or (iii) we have a certain target from data that we need to match in the model, which will constrain the calibration procedure and determine (or identify in econometric language) the value of that parameter. ${ }^{2}$ Finally, calibration is also preferred in cases when (iv) we do not have information on the parameter - when it is part of a characterization of an unobservable (latent) process, such as corruption - and want to investigate how the model predictions change when the parameter changes over a certain (plausible) range, i.e., how robust is the model to slight changes in certain parameters. Then, after calibrating all model parameters, we can proceed to simulate the model to produce artificial time series, and compare how the properties of simulated data change across the values of a particular parameter.

Regarding the variability of the parameters vs their means, the question: Why settle for a particular point estimate? is worth addressing, as by focusing exclusively on the average value, researchers are throwing up useful information. ${ }^{3}$ Thus, holding the risk aversion parameter set to its mean over the course of the business cycle might lead to potentially incorrect conclusions, as those will be based on incomplete information. Therefore, in this paper we allow the risk aversion parameter to vary over time in order to evaluate the importance of the information contained in the variability of the risk parameter for business cycle fluctuations. ${ }^{4}$ It is thus plausible to assume that a household's risk aversion can change over the business cycle. In the model setup, the risk aversion parameter shows up in the marginal rate of substitution for the household, which 
determines how consumption and labour supply decisions are made in each period, so a shock to the risk aversion parameter in turn will affect wages, interest rates, and thus production, investment, and capital accumulation decisions as well. Therefore, allowing for a stochastic risk aversion in the theoretical framework can produce additional interesting interactions among the aggregate variables in the model.

Following the argument above, this paper introduces a stochastic risk aversion parameter in a standard real-business-cycle (R B C) model with government. The model is calibrated for Bulgaria in the period 19992019, as Bulgaria provides a good testing case for the theory. ${ }^{5}$ The paper proceeds to evaluate the effect of such a stochasticity as a possible alternative mechanism of business cycle propagation. This is the first study on the issue using modern macroeconomic modelling techniques, and thus an important contribution to studies on the country's economy. Unfortunately, for reasonable degree of risk aversion variability, the quantitative effects are tiny. In particular, allowing for a stochastic risk aversion in the setup improves the model fit vis-à-vis data by increasing variability of employment and decreasing the variability of investment. However, those improvements are at the expense of decreasing the volatility of investment and wages. The small effect of the risk aversion stochasticity can be viewed as a validation of the robustness of the standard RB C model.

The rest of the paper is structured as follows: the second section presents the model framework and defines the decentralized competitive equilibrium system, the third section presents the calibration procedure, and the fourth section discusses the steady-state model solution. The fifth section proceeds with the study of the out-of-steady-state model dynamics, and evaluation of the model against data. The sixth section concludes the paper.

\section{Model Description}

There is a representative one-member household, which derives utility, and which features consumption and leisure as arguments. The total time endowment of the household can be spent in productive use or as leisure. The government taxes consumption and income to finance its purchases. Finally, on the production side, there is a stand-in firm, which rents labour and capital services to produce homogeneous final goods, which could be used for consumption, investment, or government purchases. 


\section{HOUSEHOLD'S PROBLEM}

There is a typical one-member household, which maximizes the following expected utility function

$$
\max E_{\mathrm{o}} \sum_{t=0}^{\infty} \beta^{t}\left\{\frac{c_{t}^{1-\sigma_{t}}}{1-\sigma_{t}}+\gamma \ln \left(1-h_{t}\right)\right\}
$$

where $E_{\mathrm{o}}$ operator reflects the household's expectations as of period o, $c_{t}$ is the household's private consumption in period $t, h_{t}$ denotes hours worked in period $t$, o $<\beta<1$ is the discount factor, o $<\gamma<1$ is the relative utility weight attached to leisure, and $\sigma_{t}>\mathrm{o}$ is the time-varying risk aversion parameter. ${ }^{6}$

The household begins its life with an initial stock of physical capital $k_{\mathrm{o}}>0$, and has to decide in each period thereafter how much to add to the capital stock via investment. The law of motion for physical capital is

$$
k_{t+1}=i_{t}+(1-\delta) k_{t},
$$

where $i_{t}$ is investment in period $t$, and o $<\delta<1$ is the depreciation rate. The real interest rate (before depreciation) is $r_{t}$, hence the before-tax capital income of the household in period $t$ is $r_{t} k_{t}$. In addition to capital income, the household generates labour income: hours supplied to the stand-in firm are rewarded at the hourly wage rate of $w_{t}$, so pre-tax labour income is $w_{t} h_{t}$. Lastly, the household owns the firm in the economy and receives the firm's profit, $\pi_{t}$, as income.

Next, the household's problem is now to maximize (1) subject to

$$
\left(1+\tau^{c}\right) c_{t}+k_{t+1}-(1-\delta) k_{t}=\left(1-\tau^{y}\right)\left[r_{t} k_{t}+\pi_{t}+w_{t} h_{t}\right]+g_{t}^{t}
$$

where $\tau^{c}$ is the tax on consumption ( $\left.\mathrm{VAT} / \mathrm{sales} \operatorname{tax}\right), \tau^{y}$ is the proportional income tax rate on both types of income $\left(o<\tau^{c}, \tau^{y}<1\right)$, and $g_{t}^{t}$ are government transfers, which are rebated lump-sum. The household takes the tax rates $\left\{\tau^{c}, \tau^{y}\right\}_{t=0}^{\infty}$, government transfers, $\left\{g_{t}^{t}\right\}_{t=0}^{\infty}$, profit $\left\{\pi_{t}\right\}_{t=0}^{\infty}$, the realized technology process $\left\{A_{t}\right\}_{t=0}^{\infty}$, the realized risk-aversion $\left\{\sigma_{t}\right\}_{t=0}^{\infty}$, and input prices $\left\{w_{t}, r_{t}\right\}_{t=0}^{\infty}$, and chooses $\left\{c_{t}, h_{t}, k_{t+1}\right\}_{t=0}^{\infty}$ to maximize its utility subject to the budget constraint. ${ }^{7}$ The first-order optimality conditions are as follows:

$$
c_{t}: E_{t}\left[\frac{1}{c_{t}^{\sigma_{t}}}\right]=\lambda_{t}\left(1+\tau^{c}\right)
$$




$$
\begin{aligned}
h_{t} & : \frac{\gamma}{1-h_{t}}=\lambda_{t}\left(1-\tau^{y}\right) w_{t}, \\
k_{t+1} & : \lambda_{t}=\beta E_{t} \lambda_{t+1}\left[1+\left[1-\tau^{y}\right] r_{t+1}-\delta\right], \\
\text { TVC } & : \lim _{t \rightarrow \infty} \beta^{t} \lambda_{t} k_{t+1}=0,
\end{aligned}
$$

where $\lambda_{t}$ is the Lagrangian multiplier attached to the household's $t$-period budget constraint. The first-order conditions above are interpreted as follows: the first one states that the marginal utility of consumption of the household equals the marginal utility of wealth, corrected for the consumption tax rate; note that the presence of a stochastic risk aversion parameter will play an important role in this equation. The second optimality condition describes the equilibrium in the labour market: at the margin, each hour spent by the household working for the firm should balance the benefit from doing so in terms of additional income generated, and the cost measured in terms of lower utility of leisure. The third condition is the so-called 'Euler equation,' which describes the rule for capital allocation over time. Again, there is a direct link between the shadow value $\lambda$ and the stochastic risk aversion via the first optimality condition. The last condition, the 'transversality condition' (TVC), is a boundary restriction, and is imposed to ensure stationarity: it states that at the end of the horizon, the value of physical capital should be zero in order to avoid explosive paths for capital.

\section{FIRM PROBLEM}

There is a stand-in firm in the economy, which produces a homogeneous final product, with price normalized to unity. The production technology is assumed to be Cobb-Douglas and uses both physical capital, $k_{t}$, and labour hours, $h_{t}$, as inputs to maximize profit

$$
\Pi_{t}=A_{t} k_{t}^{\alpha} h_{t}^{1-\alpha}-r_{t} k_{t}-w_{t} h_{t},
$$

where $A_{t}$ is the level of total factor productivity (TFP) in period $t$. Since the firm rents the capital from households, the problem of the firm indeed collapses to a sequence of static profit maximizing problems. In equilibrium, there are no economic profits, $\pi_{t}=0, \forall t$, and each input is priced according to its marginal product, i.e.,

$$
\begin{aligned}
& k_{t}: \alpha \frac{y_{t}}{k_{t}}=r_{t}, \\
& h_{t}:(1-\alpha) \frac{y_{t}}{h_{t}}=w_{t} .
\end{aligned}
$$


GOVERNMENT

In the model in this paper, the government taxes all forms of income, as well as consumption, in order to finance spending on government purchases $g_{t}^{c}$, and government transfers. The government budget constraint is as follows:

$$
g_{t}^{c}+g_{t}^{t}=\tau^{c} c_{t}+\tau^{y}\left[w_{t} h_{t}+r_{t} k_{t}+\pi_{t}\right]
$$

Note that government transfers would be determined residually in each period to preserve the government budget in balance. ${ }^{8}$

\section{DYNAMiC COMPETITIVE EQUiLibRium (DCE)}

For the given processes followed by technology and risk aversion, $\left\{A_{t}\right.$, $\left.\sigma_{t}\right\}_{t=0}^{\infty}$, the tax schedules $\left\{\tau^{c}, \tau^{y}\right\}_{t=0}^{\infty}$, and the initial capital stock $\left\{k_{\circ}\right\}$, the decentralized dynamic competitive equilibrium is a list of sequences $\left\{c_{t}, i_{t}, k_{t}, h_{t}\right\}_{t=0}^{\infty}$ for the household, a sequence of government purchases and transfers $\left\{g_{t}^{c}, g_{t}^{t}\right\}_{t=0}^{\infty}$, and input prices $\left\{w_{t}, r_{t}\right\}_{t=0}^{\infty}$ such that (i) the representative household maximizes its utility function subject to its budget constraint; (ii) the stand-in firm maximizes profit; (iii) the government budget is always balanced; and (iv) all markets clear.

\section{Data and Model Calibration}

To characterize business cycle fluctuations in Bulgaria, we will focus on the period 1999-2019, which is after the introduction of the currency board arrangement, which brought macroeconomic stability. Quarterly data on the main aggregate variables: output, consumption and investment, was collected from the National Statistical Institute (see www.nsi .bg), while the real interest rate is taken from the Bulgarian National Bank (see www.bnb.bg). The calibration strategy followed in this paper is as follows: first, as in Vasilev (2020b), the discount factor, $\beta=0.982$, is set to match the steady-state physical capital-to-output ratio in Bulgaria, $k / y=13.964$, in the Euler equation. The risk parameter value in steadystate was set to $\sigma=2$, which is a typical value in the literature. ${ }^{9}$ Next, the labour share, $1-\alpha=0.571$, is obtained as in Vasilev (2017d), as the average value of labour income in aggregate output over the period 19992019. Next, the average income tax rate was set to its mean value in data, $\tau^{y}=0.1$. Similarly, the average tax rate on consumption is set to its value over the period, $\tau^{c}=0.2$.

Next, parameter $\gamma$ is calibrated to match that in steady-state $h=1 / 3$, which is in line with the estimates for Bulgaria (Vasilev 2017a) as well 
TABLE 1 Model Parameters

\begin{tabular}{llll}
\hline Parameter & Value & Description & Method \\
\hline$\beta$ & 0.982 & Discount factor & Calibrated \\
$\sigma$ & 2.000 & Risk aversion & Set \\
$\alpha$ & 0.429 & Capital Share & Data average \\
$1-\alpha$ & 0.571 & Labour Share & Calibrated \\
$\gamma$ & 0.873 & Relative weight on leisure & Calibrated \\
$\delta$ & 0.013 & Depreciation rate, physical capital & Data average \\
$\tau^{y}$ & 0.100 & Average tax rate on income & Data average \\
$\tau^{c}$ & 0.200 & VAT/consumption tax rate & Data average \\
$\rho_{a}$ & 0.701 & AR(1) persistence coefficient, TFP process & Estimated \\
$\sigma_{a}$ & 0.044 & Std. error, TF P process & Estimated \\
$\rho_{s}$ & 0.701 & AR(1) persistence coefficient, risk aversion & Set \\
$\sigma_{s}$ & 0.044 & st. error, risk aversion & Set \\
\hline
\end{tabular}

over the period studied. Next, the depreciation rate of physical capital in Bulgaria, $\delta=0.013$, was estimated as in Vasilev (2016) as the average quarterly depreciation rate over the period 1999-2019. Finally, the Total factor productivity ( T F P) process is estimated from the detrended Solow residuals series by running an AR(1) specification. Due to the lack of data, we use the same parameters for the risk aversion process. Table 1 contains all parameters values used in the paper.

\section{Steady-State}

Once the model has been parameterized, and the equilibrium system has been solved for the steady-state, the 'big ratios' predicted by the model can be compared to their empirical averages in Bulgarian data, with the results reported in table 2.

The steady-state level of output was normalized to unity, which allowed for an analytical solution. Interestingly, the stochastic risk aversion plays no role in the steady-state computation. Overall, the model matches consumption-to-output and government purchases ratios by construction; the investment ratio is also closely approximated. Next, the shares of income are also identical to those in data, which is an artifact of the assumptions imposed on the functional form of the aggregate production function. Finally, the after-tax return, where $\bar{r}=\left(1-\tau^{y}\right) r-\delta$, is also relatively well-captured by the model. 
TABLE 2 Data Averages and Long-run Solution

\begin{tabular}{llll}
\hline Variable & Description & Data & Model \\
\hline$y$ & Steady-state output & N/A & 1.000 \\
$c / y$ & Consumption-to-output ratio & 0.648 & 0.674 \\
$i / y$ & Investment-to-output ratio & 0.201 & 0.175 \\
$k / y$ & Capital-to-output ratio & 13.96 & 13.96 \\
$g^{c} / y$ & Government consumption-to-output ratio & 0.151 & 0.151 \\
$w h / y$ & Labour income-to-output ratio & 0.571 & 0.571 \\
$r k / y$ & Capital income-to-output ratio & 0.429 & 0.429 \\
$h$ & Share of time spent working & 0.333 & 0.333 \\
$\bar{r}$ & After-tax net return on capital & 0.014 & 0.016 \\
\hline
\end{tabular}

\section{Out of Steady-State Model Dynamics}

Since the model does not yield an analytical solution outside the steadystate, we solve it numerically, by log-linearizing the original equilibrium system. This transformation produces a system of stochastic linear difference equations. First, we study the dynamic behaviour of model variables in response to an isolated shock to the total factor productivity, and the risk aversion process, and then we proceed to fully simulate the model in order to compare how the model performs when compared against data.

\section{IMPULSE RESPONSE ANALYSIS}

This subsection presents the impulse response functions (IR F S) of model variables to a $1 \%$ surprise innovation to technology and the risk aversion shocks, in figures 1 and 2, respectively. As a result of the technology shock, output increases upon impact, which also expands the availability of resources in the economy; thus, uses of output - consumption, investment, and government consumption - also increase contemporaneously.

At the same time, the increase in total factor productivity increases the after-tax returns on both factors of production, labour and capital. The representative household optimally responds to the incentives, and invests more, and works more. In turn, the increase in capital stock further increases output through the production function. Similarly, the increase in total hours further increases output, again indirectly.

Over time, as physical capital is being accumulated, its after-tax marginal product starts to decline, which lowers the households' incentives to save; physical capital stock eventually returns to its steady-state, and 
FIGURE 1

Impulse Responses to a $1 \%$ Surprise Innovation in Technology
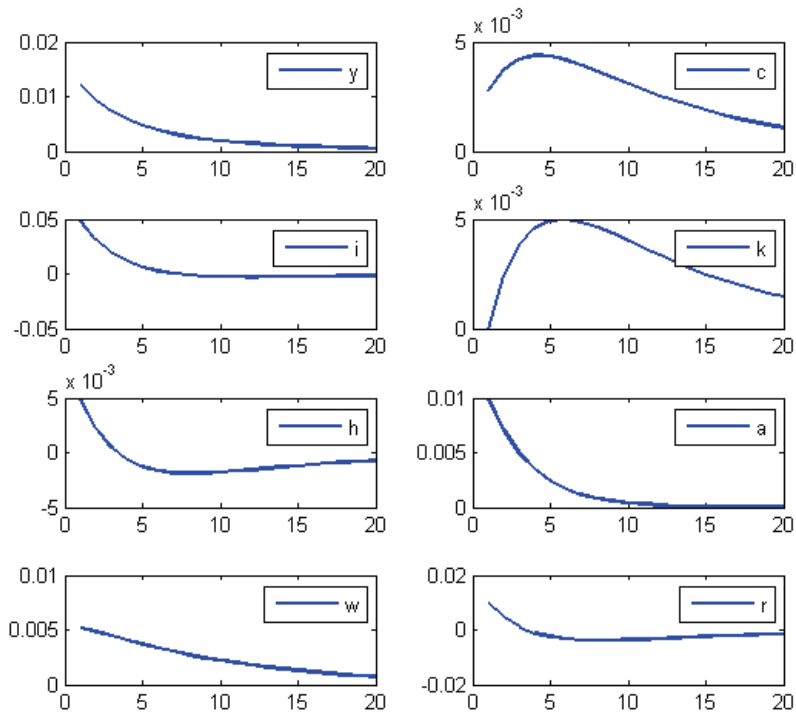

exhibits a hump-shaped dynamics over its transition path. The rest of the model variables (aside from consumption) return to their old steadystates in a monotone fashion.

Next, the quantitative effect of the shock to the risk aversion parameter, presented in figure 2, is quite small, so changes in risk aversion are unlikely candidates for business cycle propagators. In particular, upon impact of the shock, the marginal utility of consumption (the shadow price) decreases, which is why we see that consumption has increased. Investment decreases, and capital accumulation drops. Next, from the marginal rate of substitution equation, it follows that hours worked have to increase, which simultaneously decreases the wage rate. The increase in hours worked increases directly output, and indirectly the marginal productivity of capital, due to the complementarity between labour and capital in the Cobb-Douglas production function; in turn, the interest rate increases. We see this in the Euler equation, which is disturbed, as the shadow prices in both period $t$ and $t+1$ are disturbed. To preserve the balance, the interest rate in period $t+1$ needs to increase; this is because now the consumer values consumption today more relative to consumption tomorrow, which discourages investment, and thus capital stock decreases relative to its steady state. Overall, the effect of the shock to risk aversion is very short-lived, and variables return quickly to their old steady-states. 
FIGURE 2

Impulse Responses to a $1 \%$ Surprise Innovation in Technology (Flat Capital Tax Case)
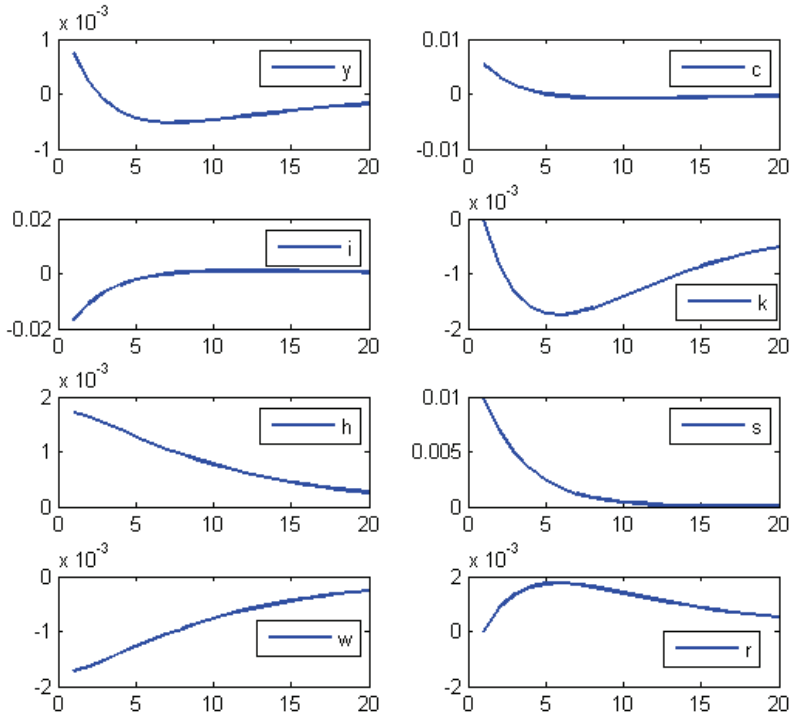

\section{SIMULATION AND MOMENT-MATCHING}

As in Vasilev (2017b), we proceed to simulate the model; both empirical and model simulated data is detrended the same way - using the Hodrick-Prescott (1980) filter. Table 3 summarizes the results. The cases considered are the setups with both shocks at work, as well as with risk aversion, and technology shocks only, respectively. As in Vasilev (2016, $2017 \mathrm{~b}, 2017 \mathrm{c}$ ), all setups match quite well the absolute volatility of output and investment. In addition, by construction, government consumption in the models varies as much as output. In the model with both shocks, the predicted consumption and investment volatilies are too high. Still, the model is qualitatively consistent with the stylized fact for Bulgaria that consumption is smoother than output, while investment is much more volatile.

In addition, the model with both shocks produces more volatile consumption and employment, and smoother investment series, relative to a setup with technology shocks alone, but the quantitative effect is rather small. Overall, the two models are almost indistinguishable from one another. The model with only shocks to risk aversion is a particularly bad fit, thus risk shocks are an unlikely candidate to cause the observed business cycles in Bulgaria.

Along the labour market dimension, the variability of employment and wages predicted by the model with both shocks is lower than that in data. 
TABLE 3 Business Cycle Moments

\begin{tabular}{|c|c|c|c|c|}
\hline Variable & (1) & (2) & (3) & (4) \\
\hline$\sigma_{y}$ & 0.05 & 0.05 & 0.05 & 0.05 \\
\hline$\sigma_{c} / \sigma_{y}$ & 0.55 & 0.89 & 2.24 & 0.82 \\
\hline$\sigma_{i} / \sigma_{y}$ & 1.77 & 2.32 & 7.74 & 2.35 \\
\hline$\sigma_{g} / \sigma_{y}$ & 1.21 & 1.00 & 1.00 & 1.00 \\
\hline$\sigma_{h} / \sigma_{y}$ & 0.63 & 0.44 & 2.59 & 0.28 \\
\hline$\sigma_{w} / \sigma_{y}$ & 0.83 & 0.78 & 2.59 & 0.86 \\
\hline$\sigma_{y / h} / \sigma_{y}$ & 0.86 & 0.78 & 2.59 & 0.86 \\
\hline $\operatorname{corr}(c, y)$ & 0.85 & 0.87 & 0.46 & 0.90 \\
\hline $\operatorname{corr}(i, y)$ & 0.61 & 0.74 & 0.08 & 0.83 \\
\hline $\operatorname{corr}(g, y)$ & 0.31 & 1.00 & 1.00 & 1.00 \\
\hline $\operatorname{corr}(h, y)$ & 0.49 & 0.33 & 0.79 & 0.59 \\
\hline $\operatorname{corr}(w, y)$ & -0.01 & 0.92 & 0.79 & 0.96 \\
\hline
\end{tabular}

Notes Column headings are as follows: (1) data, (2) both shocks, (3) risk shocks only, (4) technology shocks only.

Next, the model systematically over-predicts the pro-cyclicality of the main aggregate variables - consumption, investment, and government consumption. All those are common limitations of this class of models. In addition, the contemporaneous correlation of employment with output is too low; furthermore, the model predicts strong cyclicality, while wages in data are acyclical. This is another shortcoming in the literature, which is well known, and due to the wage being equal to the labour productivity in the model.

We proceed to discuss the auto-correlation functions (ACFS) of the major model variables. The coefficients of the empirical ACFS are presented in table 4 against the averaged simulated AFCs. For the sake of brevity, we only present the results from the setup with both shocks.

As seen from table 4, the model compares relatively well against data, even though the empirical ACFS for output and investment are slightly outside the confidence band predicted by the model; still, the ACF S for total factor productivity and household consumption are well-approximated by the model. The persistence of labour market variables are also relatively well-captured by the model dynamics. Overall, the model with both technological shocks and stochastic risk aversion is way too persistent. Next, as seen from table 5, over the business cycle, in data, employment 
TABLE 4 Autocorrelations for Bulgarian Data and the Model Economy

\begin{tabular}{llrrrr}
\hline & & \multicolumn{4}{c}{$\mathrm{k}$} \\
\cline { 3 - 6 } Method & Statistic & 0 & 1 & 2 & 3 \\
\hline Data & $\operatorname{corr}\left(n_{t}, n_{t-k}\right)$ & 1.000 & 0.484 & 0.009 & 0.352 \\
Model & $\operatorname{corr}\left(n_{t}, n_{t-k}\right)$ & 1.000 & 0.956 & 0.904 & 0.843 \\
& $($ s.e. $)$ & $(0.000)$ & $(0.027)$ & $(0.052)$ & $(0.075)$ \\
\hline Data & $\operatorname{corr}\left(y_{t}, y_{t-k}\right)$ & 1.000 & 0.810 & 0.663 & 0.479 \\
Model & $\operatorname{corr}\left(y_{t}, y_{t-k}\right)$ & 1.000 & 0.957 & 0.903 & 0.843 \\
& $($ s.e. $)$ & $(0.000)$ & $(0.025)$ & $(0.049)$ & $(0.071)$ \\
\hline Data & $\operatorname{corr}\left(a_{t}, a_{t-k}\right)$ & 1.000 & 0.702 & 0.449 & 0.277 \\
Model & $\operatorname{corr}\left(a_{t}, a_{t-k}\right)$ & 1.000 & 0.955 & 0.901 & 0.837 \\
& $($ s.e. $)$ & $(0.000)$ & $(0.027)$ & $(0.053)$ & $(0.077)$ \\
\hline Data & $\operatorname{corr}\left(c_{t}, c_{t-k}\right)$ & 1.000 & 0.971 & 0.952 & 0.913 \\
Model & $\operatorname{corr}\left(c_{t}, c_{t-k}\right)$ & 1.000 & 0.958 & 0.908 & 0.851 \\
& $($ s.e. $)$ & $(0.000)$ & $(0.025)$ & $(0.040)$ & $(0.070)$ \\
\hline Data & $\operatorname{corr}\left(i_{t}, i_{t-k}\right)$ & 1.000 & 0.810 & 0.722 & 0.594 \\
Model & $\operatorname{corr}\left(i_{t}, i_{t-k}\right)$ & 1.000 & 0.953 & 0.895 & 0.827 \\
& $($ s.e. $)$ & $(0.000)$ & $(0.029)$ & $(0.055)$ & $(0.080)$ \\
\hline Data & $\operatorname{corr}\left(w_{t}, w_{t-k}\right)$ & 1.000 & 0.760 & 0.783 & 0.554 \\
Model & $\operatorname{corr}\left(w_{t}, w_{t-k}\right)$ & $(0.000)$ & $(0.024)$ & $(0.047)$ & $(0.069)$ \\
& $(\operatorname{s.e.})$ & & & &
\end{tabular}

follows labour productivity. The current model, however, cannot capture this dynamic relationship, as in the setup, the technology shock shifts the labour demand curve, while holding the labour supply curve constant, thus producing only a contemporaneous correlation.

\section{Conclusions}

Stochastic risk aversion is introduced into a dynamic general-equilibrium setup augmented with government. The theoretical framework is calibrated to Bulgarian data for the period 1999-2019. The quantitative relevance of shocks to risk aversion is investigated for the propagation of business cycles in the Bulgarian economy. More specifically, the presence of stochastic risk aversion in the theoretical setup improves the fit vis-àvis data by increasing variability of employment and decreasing the variability of investment. However, those improvements are at the expense of 
TABLE 5 Dynamic Correlations for Bulgarian Data and the Model Economy

\begin{tabular}{llrrrrrrr}
\hline & & \multicolumn{7}{c}{$\mathrm{k}$} \\
\cline { 3 - 8 } Method Statistic & -3 & -2 & -1 & 0 & 1 & 2 & 3 \\
\hline Data & $\operatorname{corr}\left(h_{t},(y / h)_{t-k}\right)$ & -0.342 & -0.363 & -0.187 & -0.144 & 0.475 & 0.470 & 0.346 \\
Model & $\operatorname{corr}\left(h_{t},(y / h)_{t-k}\right)$ & -0.01 & -0.024 & -0.042 & -0.620 & -0.400 & -0.359 & -0.316 \\
& $($ s.e. $)$ & $(0.342)$ & $(0.299)$ & $(0.247)$ & $(0.307)$ & $(0.278)$ & $(0.308)$ & $(0.341)$ \\
\hline Data & $\operatorname{corr}\left(h_{t}, w_{t-k}\right)$ & 0.355 & 0.452 & 0.447 & 0.328 & -0.040 & -0.390 & -0.57 \\
Model & $\operatorname{corr}\left(h_{t}, w_{t-k}\right)$ & -0.01 & -0.024 & -0.042 & -0.620 & -0.400 & -0.359 & -0.316 \\
& $($ s.e. $)$ & $(0.342)$ & $(0.299)$ & $(0.247)$ & $(0.307)$ & $(0.278)$ & $(0.308)$ & $(0.341)$ \\
\hline
\end{tabular}

lowering the variability of investment and wages in the model economy. Thus, shocks to risk aversion in this context are not a likely candidate for a quantitatively important driving force behind business cycle fluctuations.

\section{Notes}

1 This is again a strong advantage to econometric estimation, which is not useful in such situations.

2 This is the case with the weight on utility of leisure.

3 As pointed out in Vasilev (2020a), an alternative approach in macroeconomic modelling is to estimate R BC models using Bayesian techniques, where each parameter is taken from a distribution.

4 Parkin (1988) uses such a technique to study whether R B C model parameters are 'structural.' Similarly, for Bulgaria Vasilev (2020a) investigates the relevance of having a stochastic capital share; Vasilev (2019a) addresses the effect of a stochastic leisure preference parameter in a standard RBC framework, while Vasilev (2019b) focuses on the quantitative effect of an endogenously determined depreciation rate in an R BC setup.

5 Bulgaria is a former transition economy, and despite the $\mathrm{EU}$ membership, it is still developing; the results could be thus relevant for other developing economies.

6 Note that the last parameter is also the inverse of the intertemporal elasticity of substitution between consumption in period $t$, and consumption in period $t+1$.

7 Note that by choosing $k_{t+1}$ the household indirectly determines investment $i_{t}$ optimally as well. That is why $i_{t}$ was excluded from the list above, as there is no separate decision made about it.

8 This assumption is not crucial in any way. Since we are abstracting from debt, which is quite low in Bulgaria, we need transfers to adjust to make the equation balance. 
9 Experimenting with a wider range of values, i.e., $\sigma \in[1,3]$ did not affect the results from the paper in any major way.

\section{References}

Hansen, G. 1985. 'Indivisible Labor and the Business Cycle.' Journal of Monetary Economics 16(3): 309-27.

Hodrick, R., and E. Prescott. 1980. 'Post-War us Business Cycles: An Empirical Investigation.' Unpublished manuscript, Carnegie-Mellon University.

Parkin, M. 1988. 'A Method for Determining Whether Parameters in Aggregative Models Are Structural.' Carnegie-Rochester Conference on Public Policy 29:215-52.

Vasilev, A. 2016. 'Progressive Taxation and (In)Stability in an Endogenous Growth Model with Human Capital Accumulation.' Journal of Economics and Econometrics 59 (2): 1-15.

- 2017a. 'Business Cycle Accounting: Bulgaria after the Introduction of the Currency Board Arrangement (1999-2014)'. European Journal of Comparative Economics 14 (2): 197-219.

- 2017b. 'A Real-Business-Cycle Model with Efficiency Wages and a Government Sector: The Case of Bulgaria.' Central European Journal of Economics and Econometrics 9 (4): 359-77.

- 2017c. 'A Real-Business-Cycle Model with Reciprocity in Labor Relations and Fiscal Policy: The Case of Bulgaria. Bulgarian Economic Papers 03-2017, Center for Economic Theories and Policies and University St. Kliment Ohridski.

- 2017d. 'VAT Evasion in Bulgaria: A General-Equilibrium Approach.' Review of Economics and Institutions 8 (2): 2-17.

- 2019a. 'How Important Are Consumer Confidence Shocks for the Propagation of Business Cycles in Bulgaria?' LEAF Working Papers, University of Lincoln.

- 2019b. 'The Role of Endogenous Capital Depreciation Rate for Business Cycle Dynamics: Lessons from Bulgaria (1999-2018).' Mimeo, University of Lincoln.

—. 2020a. 'A Real-Business-Cycle Model with a Stochastic Capital Share: Lessons for Bulgaria (1999-2018).' Margin: The Journal of Applied Economic Research 14 (1): 107-21.

- 2020b. 'Search and Matching Frictions and Business Cycle Fluctuations in Bulgaria.' International Journal of Business and Economics 19 (3): $319-40$. 
Is Human Rights Protection Good for Trade

in Africa: Evidence from Proximity

to Democratically 'Good' and 'Bad'

Neighbouring Countries

Jubril Animashaun

University of Manchester, UK

jubril.animashaun@manchester.ac.uk

University of Ilorin, Nigeria

animashaun.jo@unilorin.edu.ng

Chisom L. Ubabukoh

University of Manchester, UK

chisom.ubabukoh@manchester.ac.uk

op Jindal Global University

cubabukoh@jgu.edu.in

We study whether institutions supportive of human rights improve trade openness. Strengthening human rights institutions could reduce the adverse consequence of trade on consumers and labour rights. On the other hand, adherence could impose high transaction costs limiting the comparative advantage of many African countries. We study the effect of democratic and human rights institutions on trade openness for 40 African countries from 1960 to 2010 . To address endogeneity concerns, we exploit the variation in democracy measurement among geographically proximate neighbours with similar political histories (i.e. an inverse distanceweighted average of democracy among 'neighbours'). We find that human rights and democratic institutions increase trade in Africa. We find evidence supporting property rights, freedom of domestic movement and the political recruitment process as likely mechanisms.

Key Words: trade openness, Africa, human rights, political institutions

JEL Classification: $\mathrm{F} 1, \mathrm{~K} 38$

(c) BY.SA https://doi.org/10.26493/1854-6935.19.285-305

\section{Background}

This paper seeks to answer the question: would trade openness among African nations benefit from robust human rights, and civil and political rights institutions? The rise in international trade flows and the liberalisation of trade policy in many developing countries is a primary component 
of globalisation (Edwards 1998). As of 2014, the value of global merchandise exports as a share of GDP was 24.24 per cent, while the statistics for Africa stood at 24.26 per cent (Fouquin and Hugot 2016).

Human rights are the norms or standards that help protect people from social abuses. In many advanced states, human rights have been recognised as being an important condition for the fostering of mutually beneficial economic negotiations and trade agreements among nations (Horng 2003; Hafner-Burton 2005; 2011). They matter for trade in Africa because they could reduce the risk from predation, guard the rights of consumers and labour, and prevent ineffective trade public policies associated with many exporting states and developing countries (Anderson and Marcouiller 2002; Anderson 2008; Gansemans et al. 2017; Lin, Flachsbarth, and von Cramon-Taubadel 2020).

We test the hypothesis that improving civil and political rights and protecting human rights is an economically pragmatic option that encourages rather than reduces trade in Africa. Understanding the role of human rights in trade is particularly relevant for African countries wishing to take advantage of globalisation, while at the same time desiring to protect consumers and labour rights from the unintended consequences of trade reforms (Horng 2003; Hafner-Burton 2005; 2011). In comparative political economies, all states are committed to citizens' welfare and protection against all forms of direct and indirect aggression, victimisation and discrimination that can arise from international trade. Civil and political rights institutions help to protect people from victimisation and discrimination.

On the other hand, in developing countries, the requirement for human rights considerations could constitute political-economy obstacles to trade, due to poverty and population growth for example (Hayek 1976; Howse and Mutua 2000; Bal 2001). As evidence from nondemocratic countries suggests, democracy might not be favourable for economic reform as authoritarian governments may be more capable of initiating trade reforms (Geddes 1995). The repression of labour and civil rights may also provide a foundation for increased trade activity as they help in removing political economy obstacles to trade reform (Mitchell and McCormick 1988; Howse and Mutua 2000; De Soysa and Vadlammanati 2013). Furthermore, democratic, and legal institutions that allow for excessive lobbying, and costly and adversarial litigations could impose high transaction costs detrimental to the ease of doing business and trade.

Our study contributes to the growing awareness of the relevance of an 
open trade policy as an essential vehicle for stimulating broad-based development in Africa (Rodrik 1998). To achieve trade openness in Africa, the fifty-five member states of the Africa Union (AU) recently launched the African Continental Free Trade Area (AfCFTA). The AfCFTA aims to create a single continent-wide market for goods and services and promote the movement of capital and persons to make this possible. Although trade agreement models often assume that countries are symmetric, in reality economies differ in terms of size and levels of economic diversification. Achieving efficient outcomes from trade liberalisation among asymmetric countries could imply unfair competition with socially undesirable outcomes (Atkin 2016; UNCTAD 2019).

Perhaps the greatest challenge, from an econometric perspective, is identifying whether political rights promote trade, because evidence built on cross-country regressions is likely to produce inconsistent results due to some endogeneity issues. First, countries could have some variables which drive both trade and institutions and have been omitted from the modelling. Second, 'institutions' are multifaceted, vaguely defined, and attempts at singling out the relevant ones for trade remain scarce in the literature (Méon and Sekkat 2008). We use an Instrumental Variable (IV) approach for 45 African countries from 1960 to 2010 to study the effect of democratic and human rights institutions on trade openness. To isolate the impact of human rights, we borrow from the literature that considers a country's proximity to politically strong or weak neighbours as an instrument for empirical identification (e.g. Acemoglu et al. 2019). Our IV approach plausibly ensures that idiosyncratic changes in a country's political regime do not bias our estimates.

The resulting estimate shows that human rights institutions' effect on trade is significant and sizable irrespective of the level of economic development (lagged GDP), political instability (unrest), and after controlling for country, time and fixed effects. This ending is consistent with the literature on human rights as an important determinant of trade (Blanton and Blanton 2007), and Bojnec, Fertö, and Fogarasi (2014), which suggests that institutional quality (IQ) is important for exporting and importing countries in agro-food exports from the world's leading emerging economies. The remainder of this paper is organised as follows. The second section discusses the related literature, and the third section our identification strategy and dataset. In the fourth, we present the estimation results and the mechanisms through which democratic institutions could act as channels for trade openness. We conclude in the fifth section. 


\section{Literature Review}

Much of the literature has different claims on the role of political institutions in inducing trade reforms and promoting the trade size of export commodities (e.g. see Geddes 1995; Mansfield, Milner, and Rosendorff 2000; Bojnec, Fertő, and Fogarasi 2014). Specifically, Bojnec, Fertö, and Fogarasi (2014) discuss the impact of institutional quality (IQ) in exporting and importing countries on agro-food exports from the world's leading emerging economies using the gravity trade model and econometric panel data analysis for the period 1998-2009. Their results show that agro-food exports are positively associated with IQ and the size of the gross domestic product in exporting and importing countries but negatively with distance. For fear of losing office to rival opponents, political agents under democracies are more likely to carry out economic reforms that liberalise and promote trade (Acemoglu et al. 2019). Others such as Geddes (1995) find that countries under fragile democracies have difficulty achieving economic liberalisation, while political rights supporters demand economic reforms (Acemoglu et al. 2019), albeit through legislative deadlocks and agitation from a pressure group; the demands for economic reforms may be countered by unproductive policies such as patronage.

We hypothesise that more political rights imply a greater incentive for trade reforms and export output, especially where populations are exposed to weak political and human rights. We therefore examine how the Trade Openness Index (import and export trade as a share of GDP) depends on the quality of human rights protection. Our main contribution is the Instrumental Variable (Iv) strategy used for empirical identification. This identification method builds on Acemoglu et al. (2019), where regional waves in transitions to and away from democracy in countries with common political histories are used to investigate whether democracy causes growth. Unlike Acemoglu et al. (2019), our question examines whether human rights institutions promote trade. The political science literature emphasises the symbiotic relationship between democracy and human rights; therefore, promoting democracy as a system of government inevitably supports claims for universal human rights (Held 1992; Evans 2000, 2001). Based on this observation, our IV strategy supports the idea that the diffusion of political regimes across countries with common political histories strengthens country-level human rights institutions (Edwards et al. 2018). 
We further investigate the channels through which human rights institutions promote trade. Consistent with the hypothesis that democratic institutions encourage a suitable business environment, we find support for property rights, domestic movement of goods and persons, and the quality of the executive recruitment process as potential mechanisms supporting the result. The trend towards free trade in developing countries is often tied to the rise in democratic institutions (Milner and Kubota 2005). Intuitively, political institutions such as human rights protection matter because they can help provide an investment-friendly environment for pooling resources and safeguarding investments. For instance, democratic and human rights institutions support property rights, freedom from forced labour, and free movement of goods and persons, providing incentives for economic activities, investment, innovation, and trade, leading to a more efficient market. Furthermore, political leaders in labour-rich countries may favour lower trade barriers as democracy increases to garner political support from pressure groups (Milner and Kubota 2005). Alternative channels that rely on external pressure from Western countries or international institutions support human rights as a condition for building trade relationships are plausible.

\section{Methodology}

To test the relationship between human rights and trade, it is necessary to have a measure of human rights and trade openness. In this section, we describe how this measure is built from secondary sources for 45 African countries ${ }^{1}$ from 1960-2010. This section presents the data and the analytical framework employed for analysis. The main limitation of the investigation period is that it ignores the latest changes in most African nations' political climate, which have occurred post-2010. Nonetheless, we believe that the study period is wide enough to give us a general idea of the relationship between human rights and trade in Africa. From an econometric perspective, including later years may bring about spurious changes to the outcome since the shock to the political process in some parts of North Africa was not large enough relative to other African countries.

\section{DEPENDENT VARIABLE: TRADE OPENNESS (IMPORT AND EXPORT TRADE AS A SHARE OF GDP)}

In this study, we utilise Trade Openness, an economic metric calculated as the country's total trade (the sum of exports plus imports) to the country's gross domestic product. This metric captures all incoming and out- 
going transactions, showing the influence of trade on domestic economic activities. The data source is from Acemoglu et al. (2019).

\section{INDEPENDENT VARIABLES}

\section{Human Rights Institutions}

We use three measurements to define human rights institutions (HR).

First, we define human rights institutions ( $\mathrm{HR}$ ) as a dummy variable, observed $(\mathrm{HR}=1)$ if Freedom House regards a country $k$ in year $t-1$ as 'Free' or 'Partially Free' in terms of the amount of electoral or political rights it grants her citizens. This study regards all free or partially free countries as having political rights (human rights institutions, $\mathrm{HR}=1$ ) with the following criteria. First, if they have a competitive and multiparty political system; second, if adult citizens without criminal convictions have the right to vote in public political elections (adult suffrage); third, if they hold regularly contested elections; and lastly, if there is public access to the media of political parties for campaigns. Our classification approach is widely used in the literature, see for instance Acemoglu et al. (2019).

Our second definition of HR is also a dummy variable if Freedom House regards a country $k$ in year $t-1$ as 'Free' or 'Partially Free' in terms of the amount of civil liberties the citizens enjoy. Therefore, a country is deemed to be free if it has a substantial array of civil liberties. In both cases, Freedom House averages the score of each pair of political rights and civil liberties ratings, and scores between 1.0 and 2.5 are classified as 'Free', 3.0-5.0 as 'Partially Free', and 5.5-7.0 as 'Not Free'.

Although using the 'Free' or 'Partially Free' classifications from Freedom House to define dichotomous political institutions is a relatively common practice in the literature (e.g. see Giavazzi and Tabellini 2005; Papaioannou and Siourounis 2008; Acemoglu et al. 2019), from a purely measurement perspective, attributing quantitative values to changes in human rights institutions is a challenge. An alternative way to do this could be to count the number of human rights treaties that countries ratify. However, in practice, the agreements reached under such ratifications are not legally binding, and government authorities rarely fulfil the agreements (Hafner-Burton and Tsutsui 2005). Also, such indices are likely to be biased if they do not incorporate changes arising from raising the standards of human rights protection over time (Fariss 2014). Such classifications may also ignore or understate the changes to the standard of accountability (Fariss 2014). Therefore, our third measurement of hu- 
man rights protection is from the Fariss (2014) classification. The human rights protection score from Fariss's index is a variable that combines scores for the protection of the physical integrity of citizens using indicators of torture, government killing, political imprisonment, extrajudicial executions, mass killings and disappearances.

\section{Gross Domestic Product per Capita}

To measure the concept of economic development, we use the GDP per capita measured in constant 2000 dollars, which we obtained from the World Bank Development Indicators. The lag of GDP per capita summarises the impact of a range of economic factors that affect trade openness and human rights institutions, such as total factor productivity, political institutions and technology differences. Importantly, we could investigate a dynamic (linear) panel model by including variables of GDP per capita as regressors. The economic rationale for this is that, conditional on the lag of GDP and country fixed effects, countries with more significant trade per GDP are not on a different economic trend than those with less trade.

Additional right-hand side variables include the occurrence of events of unrest (from Acemoglu et al. 2019), the percentage of females of the total workforce and the percentage of the population within the active age range of 15 to 64 years, log of population density, the log of urbanisation index, and oil and gas rents per population in constant 2000 USD.

INSTRUMENTAL VARIABLE: THE REGIONAL DEMOCRACY SCORE

The regional democracy score variable is sourced from the replication dataset of Acemoglu et al. (2019). It utilises the advantages of historical, cultural, and political commonalities among countries in one region as important for mediating the spread of democracy and political discontent. The adoption of democratic institutions often takes place in regional waves (Markoff 2015; Acemoglu et al. 2019). Also, sudden shifts in global power often result in domestic reforms at the regional level. For instance, the second wave of democracy in Europe followed World War II, democratic reforms in the Middle East and North Africa followed the Arab Springs, and the democratic revolution in Africa followed the decolonisation drive in Sub-Saharan Africa. Social unrest and instability often led to regime change and the regional transition into democracy in all these instances. 
TABLE 1 Summary and Descriptive Statistics

\begin{tabular}{lrrrrr}
\hline Variable & $(1)$ & $(2)$ & $(3)$ & $(4)$ & $(5)$ \\
\hline $\begin{array}{l}\text { Log Trade Openness (trade exports plus } \\
\text { imports as a share of GDP X 100) }\end{array}$ & 1,916 & 404.58 & 50.17 & 214.45 & 531.7 \\
Civil Liberties, Freedom House & 1,704 & 0.17 & 0.38 & 0 & 1 \\
Political Rights, Freedom House & 1,704 & 0.20 & 0.40 & 0 & 1 \\
Log Human Rights (Fariss 2014) & 947 & -0.87 & 1.07 & -7.27 & 0.76 \\
GDP per capita (constant 2000 UsD) & 1,969 & 613 & 95.59 & 405.67 & 905.89 \\
Unrest dummy (dummy variable) & 1,879 & 0.28 & 0.45 & 0 & 1 \\
Proportion within Age bracket 15-64 & 2,070 & 52.67 & 3.31 & 46.97 & 68.81 \\
as a percentage of total population & & & & & \\
Female labour as a percentage of total & 1,936 & 40.99 & 8.36 & 16.34 & 54.12 \\
labour force & & & & & \\
Log Population Density & 2,107 & 0.03 & 0.01 & -0.003 & 0.06 \\
Oil and Gas rents per population & 2,115 & 151.44 & 875.48 & 0 & 18769 \\
Log Urbanisation index & 1,891 & 0.25 & 0.13 & 0.02 & 0.61 \\
Average democracy index in the region & 2,295 & 0.21 & 0.24 & 0 & 1 \\
\hline
\end{tabular}

NOTES Column headings are as follows: (1) observation, (2) mean, (3) standard deviation, (4) minimun, (5) maximum.

Based on this observation, we use regional waves in transitions to and transitions away from democracy as an instrument for country-level human rights measurement. Following Acemoglu et al. (2019), the instrumental variable (IV) exploits the diffusion of political institutions across countries in the same region and with shared political histories by calculating an inverse distance-weighted average of democracy among 'neighbours'. Unlike Acemoglu et al. (2019) however, we utilise this insight to answer a different research question regarding the effect of political institutions on trade openness. Our IV strategy is important to alleviate identification concerns arising from human rights institutions and the endogenous selection of rich countries into human rights institutions.

A summary of the data is presented in table 1.

\section{IDENTIFICATION STRATEGY}

This section describes the identification strategy. We estimate the effect of human rights and political institutions on trade openness using the variation in democracy measurement among geographically proximate neighbours as the instrument. 
The estimating equations are:

$$
\begin{aligned}
\mathrm{T}_{k, t} & =\delta_{\mathrm{o}}+\delta_{1} \mathrm{HR}_{k, t-1}+\delta_{2} \mathrm{GDP}_{k, t-1}+\delta_{3}^{\prime} \mathrm{R}_{k, t}+\lambda_{k}+\omega_{t}+\varepsilon_{k, t}, \\
\mathrm{HR}_{k, t-1} & =\varphi_{\mathrm{o}}+\varphi_{1} \mathrm{Z}_{k, t-1}+\varphi_{j}^{\prime} \mathrm{x}_{k, t-1}+\alpha_{k}+\mathrm{T}_{t}+\mu_{k, t},
\end{aligned}
$$

where $\mathrm{T}_{k, t}$ is the log of the trade openness index, which is the share of trade (exports plus imports) in GDP (in logs) in country $k$ at time $t$, and $\mathrm{HR}_{k, t-1}$ is the measure of the quality of human rights institutions in country $k$ at time $t-1$ (one year lag). The specification in equation (1) includes one year lag of log GDP per capita GDP $k_{k, t-1}$ on the right-hand side to control GDP dynamics; this helps to remove the mechanical effect of higher GDP on the outcome variable. This strategy allows us to remove the confounding influence of the GDP as richer countries could likely trade more than poorer countries.

${ }^{\prime} \mathrm{R}_{k, t}$ is a vector of additional right-hand side variables that include the occurrence of events of unrest dummy, the percentage of females of the total workforce and the percentage of the population within the active age range of 15 to 64 years, log of population density, the log of the urbanisation index, and oil and gas rents per population in constant 2000 USD. The country fixed effects, $\lambda_{k}$, absorbs the impact of any time-invariant country characteristics and $\omega_{t}$ denotes the time fixed effects to absorb any seasonal changes in trade outcomes each year. The error term $\varepsilon_{k, t}$ includes all other time-varying unobservable shocks to trade share per GDP.

Trade share of GDP and human rights institutions co-vary at the national level for various reasons. Therefore, simple correlations would be unlikely to reveal the causal effect. Even with the inclusion of fixed effects and GDP controls, fixed effects (FE) estimates in equation (1) are likely to be biased (Eichengreen and Leblang 2008; Decker and Lim 2009). Also, trade policy could impact political regimes. Although we lag all of our independent variables, there could be a much longer-term effect. In addition to measurement errors (Ndikumana and Baliamoune-Lutz 2007), threats to the validity of the estimates in equation (1) were reported from the presence of time-varying economic and political factors that simultaneously impact human rights institutions and trade per GDP (country fixed effects will absorb other time-invariant factors).

To consistently estimate the effect of human rights on trade, we exploit the value of regional democratisation to explain the variation in the differential movements in human rights values across the region in 
equation (2). $\mathrm{HR}_{k, t-1}$ is the human rights score, which is the endogenous regressor and $\mathrm{z}_{k, t}$ is the instrumental variable measured as the average democracy in a region excluding own country. $\mathrm{x}_{k, t-1}$ is a vector of covariates that includes other time-varying characteristics of the countries' socio-demographics in equation (1). These include the lagged GDP per capita, occurrence of events of unrest, the percentage of females of the total workforce and the percentage of the population within the active age range of 15 to 64 years, log of population density, the log of the urbanisation index, and oil and gas rents per population in constant $2000 \mathrm{USD} . \alpha_{k}$ and $\mathrm{T}_{t}$ denote the country and time fixed effects respectively to absorb any unobserved country and seasonal changes to trade outcomes.

Importantly, the instrumental variable leverages the assumption that changes in the average democracy in a region (excluding own country) have no direct effects on the aggregate trade of each country. The effect can only operate through the transition to human rights (including the country fixed effects helps absorb any other regional factors, e.g. geography, that could affect trade). We relate our approach to the one used in Acemoglu et al. (2019) and Persson and Tabellini (2009), where the regional democratisation waves are used as an exogenous source of variation in a country's likelihood of transitioning to democracy. More specifically, as in Acemoglu et al. (2019), the study exploits the variation in regional democracy score (among countries in the same region and having the same initial political regime) to identify human rights institutions.

Acemoglu et al. (2019) divide the list of countries into seven regions to compute this variable. To formalise, first a set of countries that may influence the demand for democracy in a given country is defined. For each country $k, \mathrm{D}_{k t}$ denotes whether the country was a democracy or a nondemocracy at the start of the sample. The idea behind our instrumental variable is that human rights values in country $k$ are influenced by democracy in the set of countries $\left(\mathrm{M}_{k}\right)$ surrounding $k$, which includes countries in the same region that share a similar political history.

Following Acemoglu et al. (2019), we define our instrument as:

$$
\mathrm{z}_{k, t}=\frac{1}{\left|\mathrm{M}_{k}\right|} \sum_{t=1}^{n} \mathrm{D}_{k, t},
$$

where $\mathrm{z}_{k, t}$ is the average of democracy in a region $\times$ initial regime cell excluding own-country observation. 


\section{Limitations of the Study}

There is no perfect strategy for estimating the causal effect of human rights on trade openness. Although cross country regressions will give inconsistent results, our approach employing the instrumental variable (IV) strategy is equally not free from inconsistencies. As is often the case with the IV estimator, there are no perfect instruments that will completely isolate the mechanism we are interested in. Similarly, given the limitations regarding our investigation's time frame, location, and scope, we cannot claim to have exhausted all possible mechanisms through which human rights contribute to growth. Exploring a larger time frame and incorporating interactions among political regimes that offer richer heterogeneous effects is another critical area of future inquiry.

\section{Results and Discussion}

This section is divided into three parts. The first part (table 2) examines whether human rights institutions defined as civil liberties, political rights and human rights protections significantly translate into an improvement in trade openness (share of exports and imports of GDP) in Africa. The identification strategy exploits the within-country variation and one-year lags of the independent variables to identify the effect.

In the second part (table 3), we instrument the human rights variables with the regional democracy score to causally identify the impact of human rights on trade openness.

In the third part (table 4), we examine the channels of mechanisms by replacing trade openness with property rights, freedom of domestic movement of goods and persons and the quality of the executive government recruitment process to identify the plausible channels of human rights effects on trade openness.

\section{HUMAN PROTECTION AND TRADE OPENNESS}

Table 2 reports coefficients corresponding to equation (1) and reports the within-country fixed effects $(\mathrm{FE})$ estimates for 40 African countries from 1960 to 2010. All models include controls for one-year lagged GDP per capita and time dummies as well as controls for the number of years we have valid observations in each country. Column (I) is the FE regression in which the human rights variable is defined as a dummy variable of Civil Liberties from Freedom House. Column (II) replaces the human rights variable with a dummy for political rights from Freedom House. Column (III) essentially utilises the log of human rights protection scores 
TAB LE 2 Fixed Effects Estimates: Human Rights and Trade Openness for 45 African Countries from 1960-2010

\begin{tabular}{|c|c|c|c|}
\hline Item & I & II & III \\
\hline \multirow[t]{2}{*}{ Human Rights ${ }^{\mathrm{a}}$} & 10.20 & $14.92^{*}$ & $3.82^{*}$ \\
\hline & $(7.12)$ & $(7.42)$ & $(1.95)$ \\
\hline \multirow[t]{2}{*}{ Unrest dummy } & $-6.99^{\star *}$ & $-6.23^{*}$ & 0.86 \\
\hline & $(3 \cdot 36)$ & $(3 \cdot 31)$ & $(3.38)$ \\
\hline \multirow[t]{2}{*}{ GDP per capita } & $0.30^{* * *}$ & $0.30^{* *}$ & 0.13 \\
\hline & $(0.13)$ & $(0.12)$ & $(0.11)$ \\
\hline \multirow[t]{2}{*}{ Ages $15-64$ of population } & $-2.32^{*}$ & -2.23 & -0.71 \\
\hline & $(1.31)$ & $(1.32)$ & $(0.98)$ \\
\hline \multirow[t]{2}{*}{ Females of total labour force } & 1.17 & 1.51 & -2.49 \\
\hline & $(2.55)$ & $(2.4)$ & $(2.37)$ \\
\hline \multirow[t]{2}{*}{ Population density } & $-7133^{*}$ & $-6771^{*}$ & $-10762^{* *}$ \\
\hline & （3953） & $(3636)$ & （3835） \\
\hline \multirow[t]{2}{*}{ Urbanisation index } & 19.75 & 30.28 & $-197.63^{* *}$ \\
\hline & （93） & $(87.03)$ & $(76.67)$ \\
\hline \multirow[t]{2}{*}{ Oil and Gas rents per population } & -0.0008 & -0.001 & $-0.002^{*}$ \\
\hline & $(0.002)$ & $(0.002)$ & $(0.001)$ \\
\hline F-stat & $60.76^{* * *}$ & $1543^{* * *}$ & \\
\hline Number of Countries & 40 & 40 & 32 \\
\hline Observations & 1091 & 1091 & 654 \\
\hline Country and Time Fixed Effect? & Yes & Yes & Yes \\
\hline
\end{tabular}

notes Dependent variable: Trade Openness (Trade Exports plus Imports as a share of GDP multiplied by 100). a Human Rights measured as Civil Liberties based on Freedom House in Model I, as Political Rights based on Freedom House in Model II and as Log Human rights protection based on Fariss (2014) in III. Standard errors are robust and in parenthesis. $P$-values at less than $0.01,0.05$ and 0.1 are indicated as ${ }^{* *},{ }^{* *}$ and ${ }^{*}$ respectively.

from Fariss's (2014) paper to define human rights institutions, which involves accounting for the changes in the way human rights are accounted for over the years. All specifications in table 2 indicate a weak (columns II and III) and statistically insignificant association (column I). The estimated weak coefficient on human rights variables suggests that the models reported in table 2 may be mis-specified.

Nevertheless, an important finding indicates that the effect of the human rights variables is broadly consistent across models (especially 
columns II and III). As expected, countries with better human rights tend to have better political institutions, be more productive, have higher income and engage more in trade (table 2). This supports our hypothesis that human rights institutional development displays some state dependence and is likely to exhibit bi-directional causality with trade openness.

\section{EFFECT OF HUMAN RIGHTS PROTECTION ON TRADE}

OPENNESS

Table 3 (panel A) reports the main instrumental variable results (equations (1) and (2)). In panel B, we report the corresponding first stage estimates and the diagnostic tests. The previous estimates reported in table 2 do not correct for the potential endogeneity. Throughout, the reported coefficients on human rights institution variables are multiplied by 100 to ease its interpretation, and we report standard errors robust against heteroscedasticity. Across the three models in table 3, the resulting estimates of human rights impact on trade share of GDP are similar. In essence, conditioning trade on human rights institutions increases trade share of GDP irrespective of GDP per capita and other controls.

Table 3 supports the positive and significant contribution of human rights to trade in Africa. All estimates are positive and significant at the 5 per cent level (or below). Specifically, in column (IV), we find that the effect of human rights is (defined as a dummy that measures civil liberties) positive and highly significant, with a coefficient of 71.23. In column $\mathrm{v}$, we find that human rights defined with political rights positively affect trade with a coefficient of 32.17 . In columns IV and v, countries with civil liberties and political rights will experience a 71 per cent and 32 per cent increase in trade as a share of GDP. In column VI, we find that trade openness improves by 47.54 per cent with a 1 per cent increase in the log of human rights protection. The broad similarity of these results (table 3 ) and the difference with estimates presented in table 2 reflects, in part, the concerns regarding the endogeneity of institutions. As shown in panel B of table 3 , the first-stage results and diagnostic tests for weak instruments fail to reject the null hypothesis of weak identification. Also, the instrument performs reasonably well in improving the estimates.

MECHANISMS: DEMOCRATIC INSTITUTIONS AS CHANNELS FOR TRADE OPENNESS

The substantial effect of civil liberties, political rights and the protection of human rights on trade openness in table 3 , though not surprising, is in- 
TABLE 3 FE 2-SLS Estimates of the Effect of Human Rights on (Log) Trade Openness for 45 African countries from 1960-2010

\begin{tabular}{|c|c|c|c|}
\hline & \multicolumn{3}{|c|}{ Panel A: FE 2-SLS Estimates } \\
\hline & IV & $\mathrm{v}$ & VI \\
\hline \multirow[t]{2}{*}{ Human Rights $^{\mathrm{a}}$} & $71.23^{\star * *}$ & $32.17^{* *}$ & $47.54^{\star * *}$ \\
\hline & $(26.22)$ & $(14.8)$ & $(17.97)$ \\
\hline \multirow[t]{2}{*}{ Unrest dummy } & -2.29 & $-4.45^{*}$ & 6.91 \\
\hline & $(2.8)$ & $(2.29)$ & $(6.94)$ \\
\hline \multirow[t]{2}{*}{ GDP per Capita } & $0.23^{* * *}$ & $0.31^{* * *}$ & -0.04 \\
\hline & $(0.05)$ & $(0.04)$ & $(0.13)$ \\
\hline \multirow[t]{2}{*}{ Ages $15-64$ of population } & $-3.21^{* * *}$ & $-2.29^{* * *}$ & 0.28 \\
\hline & $(0.7)$ & $(0.54)$ & $(1.35)$ \\
\hline \multirow[t]{2}{*}{ Females of total labour force } & $2.93^{* *}$ & $2.25^{\star *}$ & 3.56 \\
\hline & $(1.27)$ & $(1.06)$ & $(4.21)$ \\
\hline \multirow[t]{2}{*}{ Population density } & $-4318^{\star *}$ & $-5809^{\star * *}$ & $-9287^{* *}$ \\
\hline & $(2104)$ & $(1666)$ & $(3645)$ \\
\hline \multirow[t]{2}{*}{ Urbanisation index } & $91.64^{*}$ & 56.33 & -48.45 \\
\hline & $(48.05)$ & $(38.47)$ & (121.9) \\
\hline \multirow[t]{2}{*}{ Oil and Gas rents per population } & -0.001 & -0.002 & $-0.01^{* *}$ \\
\hline & $(0.002)$ & $(0.002)$ & $(0.004)$ \\
\hline $\begin{array}{l}\text { Under-identification test (Kleibergen-Paap rk LM } \\
\text { statistics) }\end{array}$ & $16.41^{* * *}$ & $36.95^{* * *}$ & $8.388^{\star *}$ \\
\hline Cragg-Donald Wald F statistic & 19.12 & 40.5 & 5.64 \\
\hline Kleibergen-Paap rk Wald F-stat & $15 \cdot 34$ & 40.48 & 8.03 \\
\hline Number of Countries & 40 & 40 & 32 \\
\hline Observations & 1091 & 1091 & 654 \\
\hline Country and Time Fixed Effect? & Yes & Yes & Yes \\
\hline
\end{tabular}

NOTES Dependent variable: Trade Openness (trade exports plus imports as a share of GDP multiplied by 100). ${ }^{a}$ Human Rights measured as Civil Liberties based on Freedom House in Model IV, as Political Rights based on Freedom House in Model v and as Log Human Rights protection based on Fariss (2014) in VI. Standard errors are robust and in parenthesis. $P$-values at less than $0.01,0.05$ and 0.1 are indicated as ${ }^{* *},{ }^{* *}$, and ${ }^{*}$, respectively.

Continued on the next page

triguing. By citing the case of some Latin American countries, e.g. Chile, this evidence indicates that autocratic and nondemocratic governments are both likely to liberalise trade (Geddes 1995). External pressures could 
TAB LE 3 Continued from the previous page

\begin{tabular}{lccc}
\hline & \multicolumn{3}{c}{ Panel B: First Stage Estimates } \\
\cline { 2 - 4 } Instrumental Variable & $(1)$ & $(2)$ & $(3)$ \\
\hline Regional Democracy & $0.51^{* * *}$ & $0.79^{\star * *}$ & $1.59^{\star *}$ \\
& $(0.13)$ & $(0.12)$ & $(0.56)$ \\
F-test of Excluded instruments & $15.84^{* * *}$ & $40.49^{\star * *}$ & $8.03^{\star *}$ \\
Underid (sw Chi-sq) & $16.47^{\star * *}$ & $42.05^{\star * *}$ & $8.75^{\star *}$ \\
Weak id (sw F) & 15.84 & 40.49 & 8.03 \\
\hline
\end{tabular}

NOTES Instrumented variable: Human Rights. Column headings are as follows: (1) Civil liberties, (2) political rights, (3) human rights protection. $P$-values at less than 0.01, 0.05 and 0.1 are indicated as ${ }^{\star * *},{ }^{* *}$, and ${ }^{\star}$, respectively.

explain this, for example, the influence of Western countries in general, or international agencies like the World Trade Organization (w To) that force countries to reform human rights and political institutions in order to partake in trade. Other contrasting arguments suggest that democratic institutions were not necessarily promising for economic reform. This implies that we need to look for alternative explanations to explain the relationship.

The first channel we investigate is improving the quality of the executive recruitment process associated with human rights reforms. Human rights reforms could provide incentives for democratisation, measured by the quality and transparency of the recruitment of executives into public offices. How could political leaders in many developing countries choose to lower their trade barriers when citizens have more liberties and freedom? The standard political economy models predict that if power is concentrated in the hands of a few interest groups, they will likely resist any move towards reforms that lower barriers to trade if they fear that such reforms will diffuse benefits to a larger group. On the other hand, human rights reforms are likely to usher in a new era of democratisation and improve political competition. With constraints to reduced political participation, politically-minded leaders will recognise the strength of the previously disenfranchised groups and use favourable trade policy to appeal for votes to ensure political survival (see Milner and Kubota 2005). Human rights reforms can alter the political calculus and induce a shift in the optimal choice of trade reforms that benefit a larger segment of the voters.

The second channel that we explore is the improvement in property 
rights due to progress in human rights. Since the time of Adam Smith, economists have long been aware that property rights are crucial for economic development (Knack and Keefer 1995). A potential investor may choose not to invest in any productive activity that requires a substantially fixed capital outlay in the absence of any protection on investment. The implication is a reduction in economic investments, tradeable exports, and labour and capital relocation to areas with greater property rights and investment protection. However, any government strong enough to institute property rights is also likely to have the power to abrogate those rights as well (North and Weingast 1989). This is where human rights reform could be essential for safeguarding property rights and ensuring governments' commitment to upholding the requirements.

The third channel we explore is the freedom of domestic movement of factors of production. Policies that restrict the movement of persons and goods will reduce economic freedoms and the freedom of individuals to engage in international exchange. With domestic freedom, individuals will produce a larger output and achieve a higher income level than would otherwise be possible. Because freedom of movement and international exchange promotes entrepreneurial and innovative activities, one should expect individuals with greater human rights, civil liberties, and political rights to have higher levels of freedom of local and international exchange and improvement in trade.

We put these three mechanisms to the test in table 4 . We estimate equation (4) after the first stage of equation (2).

$$
\mathrm{M}_{k, t}=\delta_{\mathrm{o}}+\delta_{1} \mathrm{HR}_{k, t-1}+\delta_{2} \mathrm{GDP}_{k, t-1}+\delta_{3} \mathrm{R}_{k, t}^{\prime}+\lambda_{k}+\omega_{t}+\varepsilon_{k, t},
$$

where $\mathrm{M}_{k, t}$ is one of the three mechanisms of quality of the executive recruitment process, property rights and freedom of goods and persons in country $k$ at time $t$, and $\mathrm{HR}_{k, t-1}$ is the measure of the quality of human rights institutions in country $k$ at time $t-1$ (one year lag). The specification in equation (4) includes the one-year lag of log GDP per capita $\mathrm{GDP}_{k, t-1}$ as a regressor to control for GDP dynamics; it helps to remove the mechanical effect of higher GDP on the outcome variable. $\mathrm{R}_{k, t}^{\prime}$ is a vector of additional right-hand side variables that include the occurrence of events of unrest dummy, the percentage of females of the total workforce and the percentage of the population within the active age range of 15 to 64 years, log of population density, the log of the urbanisation index, and oil and gas rents per population in constant 2000 USD. The country fixed effect, $\lambda_{k}$ absorbs the impact of any time-invariant country 


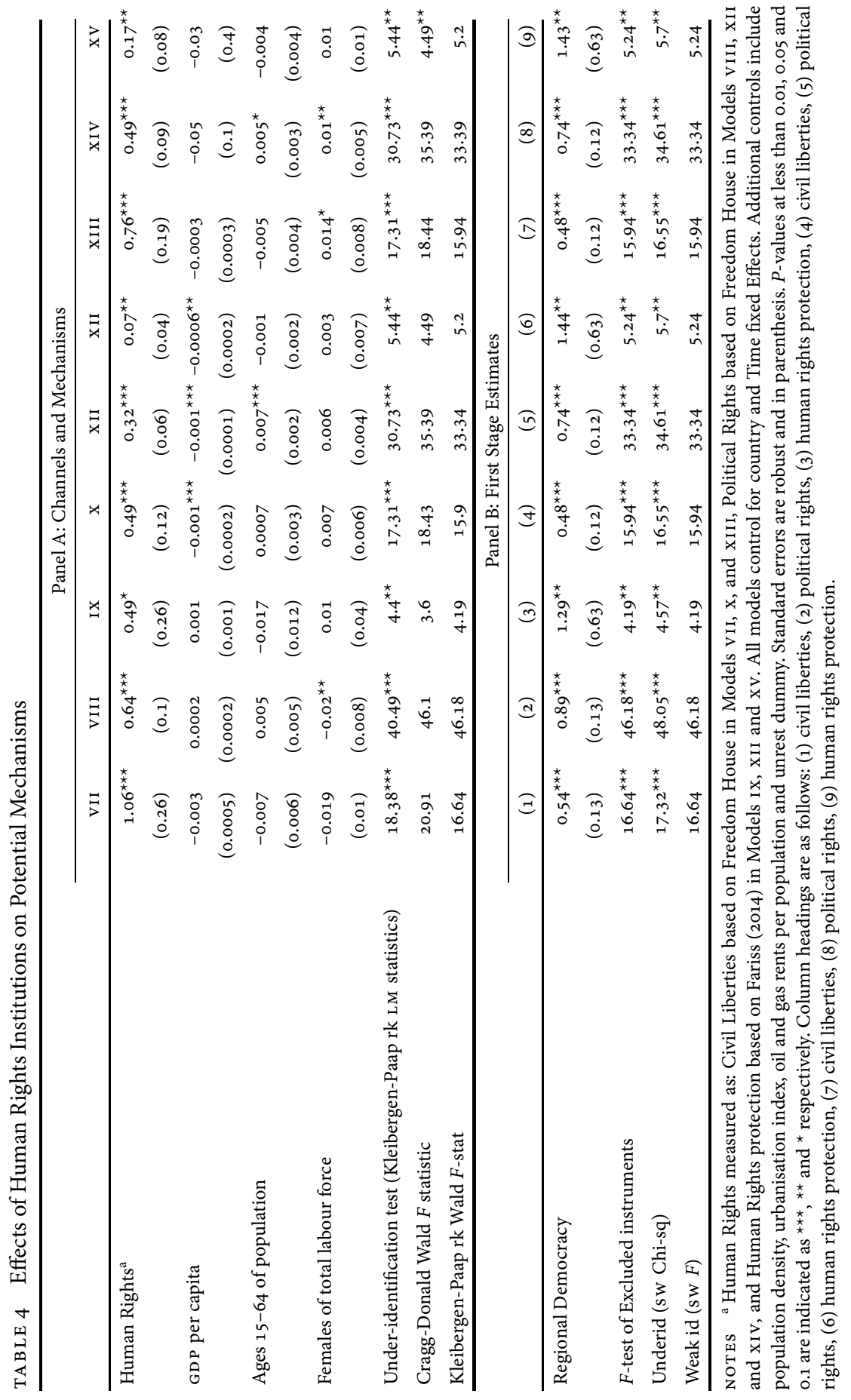


characteristics and $\omega_{t}$ denotes the time fixed effects to absorb any seasonal changes in trade outcomes each year. The error term $\varepsilon_{k, t}$ includes all other time-varying unobservable shocks to trade share per GDP.

In all the channels (table 4), we find that human rights institutions defined by civil liberties, political rights and human rights protection increase the quality of the executive recruitment process, property rights and the freedom of domestic movement of goods and services. Overall, these results suggest that human rights institutions might be working these channels to improve trade.

Several other arguments could be proposed. For instance, a focus on external pressures, mainly from the Us, the $\mathrm{EU}$ or multinationals like the IMF and WTO, could be investigated. These countries and organisations can make human rights a condition for international trade. A counterargument to this would be the rise of the countries in South Asia and China. They have been able to utilise trade to bolster economic development despite having relatively weaker human rights records. Besides, the rise of competition between the Us and China for trading partners provides suitable alternative trading partners for countries who do not wish to improve their human rights records. Therefore, this channel might seem less capable of explaining how human rights reforms can make developing countries improve trade.

\section{Conclusion}

We investigate whether human rights and democratic institutions promote trade and understand some of the mechanisms of 45 African countries using data from 1960 to 2010 . We argue that this is an important and timely question given the lack of clarity and support for the economic importance of human rights institutions, especially in developing countries.

To address the endogeneity concerns, we exploit the source of variation in regional waves of democratic transition (excluding own country) to identify the effect of human rights institutions on trade openness. Our first stage results show that regional waves in democratic transition support adopting human rights standards: a country surrounded by countries practising democracy is more likely to adopt human rights institutions. We show a statistically significant positive impact of human rights institutions (civil liberties, political rights, and protecting human rights from abuse and indiscriminate arrests) on trade (import and export as a share of GDP per capita). Our results are consistent with related literature like Blanton and Blanton (2007), and Bojnec, Fertö, and Fogarasi 
(2014) who show the importance of human rights on trade and institutional quality on food exports respectively but illustrate these ideas for the first time using data from African countries.

Our evidence also suggests that human rights foster trade. The channels we identify include improving the quality of executive recruitment, property rights and the freedom of movement of goods and persons. These channels promote trade because they are likely to induce greater investment by guaranteeing the protection of factors of production. Taken together, our results suggest that human rights institutions are not a hindrance to trade, but instead, there are many complementarities between favourable political institutions, investment climate and economic development.

\section{References}

Acemoglu, D., S. Naidu, P. Restrepo, and J. A. Robinson. 2019. 'Democracy Does Cause Growth.' Journal of Political Economy 127 (1): 47-100.

Anderson, J. E. 2008. 'Trade and Informal Institutions.' In Handbook of International Trade, edited by Choi, E. K., and J. C. Hartigan, 279-93. Oxford: Blackwell.

Anderson, J. E., and D. Marcouiller. 2002. 'Insecurity and the Pattern of Trade: An Empirical Investigation.' Review of Economics and Statistics 84 (2): 342-52.

Atkin, D. 2016. 'Endogenous Skill Acquisition and Export Manufacturing in Mexico.' American Economic Review 106 (8): 2046-85.

Bal, S. 2001. 'International Free Trade Agreements and Human Rights: Reinterpreting Article xx of the Gat T.' Minnesota Journal of Global Trade 191. https://scholarship.law.umn.edu/mjil/191.

Blanton, R. G., and S. L. Blanton. 2007. 'Human Rights and Trade: Beyond the "Spotlight". International Interactions 33(2): 97-117.

Bojnec, Š., I. Fertö, and J. Fogarasi. 2014. 'Quality of Institutions and the B RIC Countries Agro-Food Exports.' China Agricultural Economic Review 6 (3): 379-94.

De Soysa, I., and K. C. Vadlammanati. 2013. 'Do Pro-Market Economic Reforms Drive Human Rights Violations? An Empirical Assessment, 1981-2006.' Public Choice 155 (1-2): 163-87.

Decker, J. H., and J. J. Lim. 2009. 'Democracy and Trade: An Empirical Study'. Economics of Governance 10 (2): 165-86.

Edwards, S. 1998. 'Openness, Productivity and Growth: What Do We Really Know?' The Economic Journal 108 (447): 383-98.

Edwards, T. H., D. Kernohan, T. Landman, and A. Nessa. 2018. 'Good Neighbours Matter'. Spatial Economic Analysis 13 (3): 319-37. 
Eichengreen, B., and D. Leblang. 2008. 'Democracy and Globalisation.' Economics \& Politics 20 (3): 289-334.

Evans, T. 2000. 'Globalisation, Human Rights and International Citizenship.' Alternatives 25 (4): 415-38.

- 2001. 'If Democracy, Then Human Rights?' Third World Quarterly 22 (4): 623-42.

Fariss, C. J. 2014. 'Respect for Human Rights Has Improved Over Time.' American Political Science Review 108 (2): 297-318.

Fouquin, M., and J. Hugot. 2016. 'Two Centuries of Bilateral Trade and Gravity Data: 1827-2014'. Working Paper 14, CE PII, Paris.

Gansemans, A., D. Martens, M. D’Haese, and J. Orbie. 2017. 'Do Labour Rights Matter for Export? A Qualitative Comparative Analysis of Pineapple Trade to the EU. Politics and Governance 5 (4): 93-105.

Geddes, B. 1995. 'Challenging the Conventional Wisdom.' In Economic Reform and Democracy, edited by L. Diamond and M. Plattner, 59-73. Stanford, ca: Stanford University Press.

Giavazzi, F., and G. Tabellini. 2005. 'Economic and Political Liberalizations.' Journal of Monetary Economics 52 (7): 1297-330.

Hafner-Burton, E. M. 2005. 'Trading Human Rights: How Preferential Trade Agreements Influence Government Repression.' International Organization 59 (3): 593-629.

- 2011. Forced to be Good: Why Trade Agreements Boost Human Rights. Ithaca, NY: Cornell University Press.

Hafner-Burton, E. M., and K. Tsutsui. 2005. 'Human Rights in a Globalising World: The Paradox of Empty Promises.' American Journal of Sociology 110 (5): 1373-1411.

Hayek, F. 1976. Law, Legislation and Liberty. Vol. 2, The Mirage of Social Justice. Chicago: University of Chicago Press.

Held, D. 1992. 'Democracy: From City-State to Cosmopolitan Order.' Political Studies 40 (Special Issue): 10-39.

Horng, D. C. 2003. 'The Human Rights Clause in the European Union's External Trade and Development Agreements.' European Law Journal 9 (5): 677-701.

Howse, R., and M. Mutua. 2000. Protecting Human Rights in a Global Economy: Challenges for the World Trade Organization. Montreal: International Centre for Human Rights and Democratic Development.

Knack, S., and P. Keefer 1995. 'Institutions and Economic Performance: Cross-Country Tests Using Alternative Institutional Measures.' Economics \& Politics 7 (3): 207-27.

Lin, J., I. Flachsbarth, and S. von Cramon-Taubadel. 2020. 'The Role of Institutional Quality on the Performance in the Export of Coconut Products.' Agricultural Economics 51 (2): 237-58. 
Mansfield, E. D., H. V. Milner, and B. P. Rosendorff. 2000. 'Free to Trade: Democracies, Autocracies, and International Trade.' Americal Political Science Review 94 (2): 305-21.

Markoff, J. 2015. Waves of Democracy: Social Movements and Political Change. London: Routledge.

Méon, P. G., and K. Sekkat. 2008. 'Institutional Quality and Trade: Which Institutions? Which Trade?' Economic Inquiry 46 (2): 227-40.

Milner, H. V., and K. Kubota. 2005. 'Why the Move to Free Trade? Democracy and Trade Policy in the Developing Countries.' International Organisation 59 (1): 107-43.

Mitchell, N. J., and J. M. McCormick. 1988. 'Economic and Political Explanations of Human Rights Violations.' World Politics 40 (4): 476-98.

Ndikumana, L., and M. Baliamoune-Lutz. 2007. 'The Growth Effects of Openness to Trade and the Role of Institutions: New Evidence from African Countries.' Working Paper 5, University of Massachusetts, Amhurst, MA.

North, D. C., and B. R. Weingast. 1989. 'Constitutions And Commitment: the Evolution of Institutions Governing Public Choice in SeventeenthCentury England.' The Journal of Economic History 49 (4): 803-32.

Papaioannou, E., and G. Siourounis. 2008. 'Democratisation and Growth.' The Economic Journal 118 (532): 1520-51.

Persson, T., and G. Tabellini. 2009. 'Democratic Capital: The Nexus of Political and Economic Change.' American Economic Journal: Macroeconomics 1 (2): 88-126.

Rodrik, D. 1998. 'Trade Policy and Economic Performance in Sub-Saharan Africa.' Working Paper 6562, National Bureau of Economic Research, Cambridge, MA.

unCtA D. 2019. Trade Policies for Combating Inequality: Equal Opportunities to Firms, Workers and Countries. New York: United Nations. 



\title{
Foreign Aid and Economic Development in Sub-Saharan Africa: The Mediating Role of Governance Effectiveness
}

\author{
Richard Ilorah \\ University of Limpopo, South Africa \\ richard.ilorah@gmail.com \\ Collins C. Ngwakwe \\ University of Limpopo, South Africa \\ collins.ngwakwe@ul.ac.za
}

This paper aims to analyse the effect of foreign aid, moderated by governance effectiveness variables, on economic development in sub-Saharan Africa. Data on foreign aid, GDP and governance variables were from the World Bank governance archives covering five sub-Saharan African countries. The paper applied the oLs and fixed effect panel multiple regression analysis. From the first analysis, findings show a negative link between external aid and GDP per capita in sub-Saharan Africa. In the second analysis with governance moderating variables, findings indicate a positive relationship between foreign aid and GDP with rule of law providing a positive boost to foreign aid and GDP growth, but corruption and governance have a negative relationship with economic growth. The paper highlights policy implications for the need to bridle corruption and to strengthen governance institutions to enable foreign aid to function effectively toward economic growth. The paper suggests an agenda for further research to apply more governance institution variables in further analysis of aid effectiveness in sub-Saharan Africa economic growth.

Key Words: foreign aid, economic development, governance institutions, poverty JEL Classification: M2, O1

(c) BY-SA https://doi.org/10.26493/1854-6935.19.307-326

\section{Introduction}

The role of foreign aid in managing the development of transition economies continues to be contentious and non-conclusive in global transitions literature. It is important to recognise that how the government applies the foreign aid to local investment does matter in boosting the effectiveness of foreign aid. This is why Ioan and Ioan (2016) highlight the im- 
portance of clear direction and quality of investment in promoting economic growth. In addition, well-functioning economic institutions are very important in directing the course of economic growth (Žižmond and Novak 2006). Africa's prevalent reliance on external aid has largely provoked a well-being mindset in the continent (Easterly 2002). Aid to sub-Saharan Africa (s A) remains significant: during 2005-2013, the region received about 88 percent of the U $\$ 416.9$ billion in official aid to the African continent (OECD 2014). Earlier, during 1980-2004, the continent received U $\$ 716.15$ billion in official aid, with over 65 percent of that total allocated to ss A (Lal and Rajapatirana 2007).

However, some researches argue that in some instances, the benefit of aid to recipient countries does not reflect on the pace of economic growth. For instance, some researches express the negative sentiment that aid to some countries has rather encouraged poor accountability and deeper dependence, and promoted dysfunctional institutions (Grabowski 2006). However, it does seem that aid-led economic growth has not been noticeable for sub-Saharan Africa. Hence, critics of aid question the effectiveness of aid to reduce poverty and promote development, especially in the absence of selectivity in aid allocation (Bhagwati 2010). Therefore, aid and economic development within sub-Saharan Africa remain a conundrum, which requires unceasing research inquiry and solutions, especially considering that sub-Saharan Africa is a region lagging behind in global transition (UNDP 2021). It presents a unique analysis wherein the aid and development nexus is conducted first and then the governance mediating variables are included in a second analysis.

Research on external aid and development in Africa has had variegated results (Mallik 2008). Some researchers find a significant link between external aid and economic growth (Adebayo and Beton Kalmaz 2020). Others find a negative link between aid and economic growth (Ismail 2020). Yet others insist that foreign aid relates to economic development in sub-Saharan Africa (Mbah and Amassoma 2014). However, many researchers have overlooked that the government bureaucrats are in charge of overseeing the application of foreign aid in local investments. Hence, the effectiveness of governance should be brought into the analysis of whether foreign aid does promote economic growth in sub-Saharan Africa. This paper contributes by controlling the foreign variable with government institution variables (namely corruption control, rule of law and government effectiveness) in examining the influence of foreign aid on economic growth in sub-Saharan Africa. 
TABLE 1 Sub-Saharan Africa Foreign Aid (FAid) Received, and GDP per Capita

\begin{tabular}{lrrrrrrr}
\hline Year & $(1)$ & $(2)$ & & Year & $(1)$ & $(2)$ \\
\cline { 1 - 2 } 2000 & 3.42 & $1,227.74$ & & 2010 & 3.36 & $1,592.59$ \\
2001 & 3.92 & $1,246.97$ & 2011 & 3.20 & $1,620.10$ \\
2002 & 4.80 & $1,291.81$ & 2012 & 2.98 & $1,641.14$ \\
2003 & 5.01 & $1,311.73$ & 2013 & 2.86 & $1,677.76$ \\
2004 & 4.28 & $1,360.29$ & 2014 & 2.66 & $1,711.91$ \\
2005 & 4.48 & $1,404.48$ & 2015 & 2.77 & $1,712.18$ \\
2006 & 4.67 & $1,453.91$ & 2016 & 2.95 & $1,685.68$ \\
2007 & 3.57 & $1,506.95$ & 2017 & 3.12 & $1,683.09$ \\
2008 & 3.48 & $1,545.13$ & 2018 & 3.04 & $1,681.38$ \\
2009 & 3.97 & $1,550.24$ & 2019 & 3.23 & $1,675.68$ \\
\hline
\end{tabular}

NOTES Column headings are as follows: (1) foreign aid (percentage of GNI), (2) GDP per capita (constant 2010 U s\$). Based on data from World Bank (see https://datacatalog .worldbank.org).

The rationale and hence the need for this paper intertwines around the problem of lack of significant economic growth and the high rate of poverty in sub-Saharan Africa. Despite many years of aid dependency (table 1), sub-Saharan Africa has little pragmatic evidence of aid-led economic growth. Yet the region accounts for the highest aid dependency ratio, more than other regions of the world, and whereas it is expected that aid in sub-Saharan would engender growth for poverty reduction, this has not matured as desired. Sub-Saharan Africa continues to account for the lowest economic growth and highest level of poverty amongst the world's regions; hence, global transition to sustainable development by 2030 appears elusive in this region of the world. Therefore, this paper is important as it contributes toward efforts to find solutions to the problem of lack of aid effectiveness on growth - in this instance, this paper focuses on how governance effectiveness variables might mar or improve aid effectiveness. This paper's focus on sub-Saharan Africa is unique because the region is trailing behind in the race for sustained growth and development, and is still in dire need of solutions to lift the region out of its economic and social woes. Hence, research papers such as this are most pertinent to provide empirical suggestions that may contribute in lifting the region to a better trajectory of economic growth and development.

Table 1 shows the foreign aid (official development assistance $=$ ODA as $\%$ of GNI) received into sub-Saharan Africa and the sub-Saharan African 


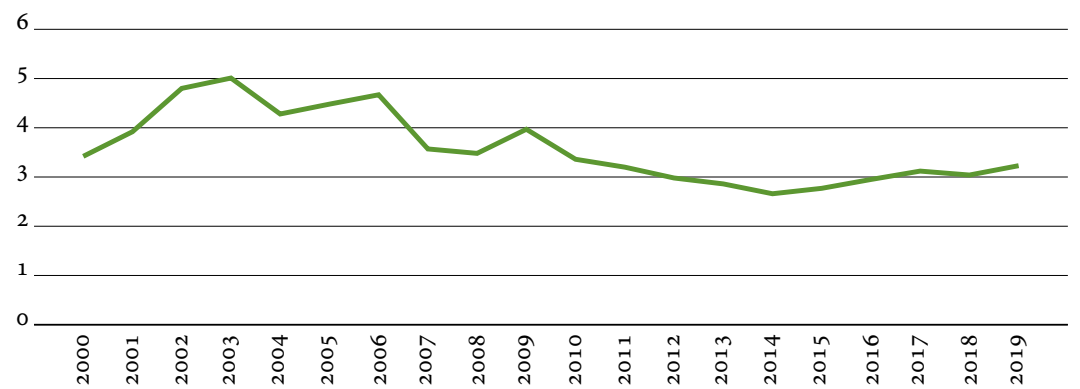

FIGURE 1 Sub-Saharan Africa Foreign Aid Received (Percentage of GNI)

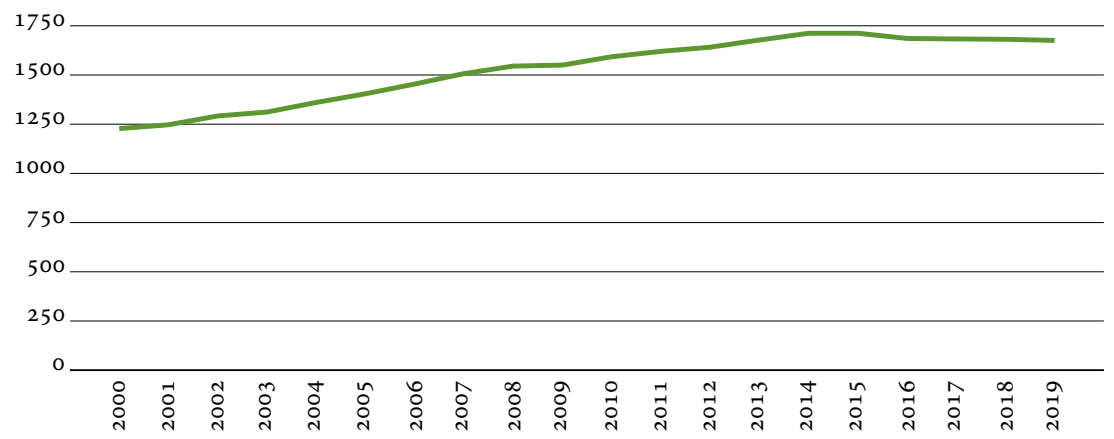

FIgURE 2 Sub-Saharan Africa GDP per Capita (Constant 2010 US\$)

economic growth (GDP per capita) for twenty years (2000-2019). Figures 1 and 2 show the line trend of foreign aid (ODA) received (as percentage of GNI) and GDP per capita for sub-Saharan Africa for twenty years.

The problem of this paper pivots on weak economic growth and development in sub-Saharan Africa amidst aid receipt over the years. Much blame has often been ascribed to the international obstacles to growth with little attention on national institutional problems such as corruption, which some researchers bemoan as a factor that weakens governance effectiveness toward economic policies and hence weakens the rule of law. By extension, institutional economics theorists attribute weak institutions in sub-Saharan Africa as debilitating foreign aid's influence on growth. However, these institutional variables such as corruption, rule of law, and governance effectiveness, have barely been subjected to empirical test along with foreign aid within the region to evaluate how a combination of the variables may influence economic growth. This current paper aspires to this unique analysis.

Accordingly, the objective of this paper is to analyse the influence of 
foreign aid, moderated by government effectiveness variables (corruption, rule of law and governance effectiveness), on economic development in sub-Saharan Africa. It aims to first ascertain if foreign aid has a positive or negative relationship to sub-Saharan Africa economic development (Omoteso and Mobolaji 2014). Therefore, this paper rests on a fundamental research question, namely how does foreign aid influence economic development in sub-Saharan Africa when moderated by government effectiveness variables.

\section{Literature Review}

Minoiu and Reddy (2010) studied the impact of official development assistance on the growth of developing economies. They applied a different approach from previous research by separating aid meant for development and aid specifically targeted at development. Their analysis also provides a basis for further research to conduct a long-term evaluation of the effect of aid on growth. Their findings show that the developmental type of aid has a significant influence on the enhancement of longterm economic growth in developing countries. They also postulate that donors prioritise their donation to enhance development and productive relationships with the recipients and thirdly that some donors shelve excessive strategic bottlenecks to promote political institutions that prioritise development policies.

Other researchers argue and find empirically that this is not often the case, that in some instances, aid has not occasioned the desired economic development (Rajan and Subramanian 2008; Minoiu and Reddy 2010). In addition, they cite Kilby and Dreher (2010) to argue and provide a caution that it is not always the case that the recipient characteristics invalidate the effectiveness of aid. Rather, the motive behind the donor and the disbursement attributes may have an important effect on how the aid affects development - a character quite separate from the quality of the recipient (Kilby and Dreher 2010).

Contrary to the earlier findings, Das and Sethi (2019) evaluate the impact of external direct investment, official development assistance, and remittances on the economic development of Sri Lanka and India. They applied time series analysis for both countries from 1980 to 2016 and considered both short-term and long-term impacts of the external aid on development. Their findings show that foreign direct investment combined with remittances stimulates economic growth in India. However, for Sri Lanka, economic growth derives from the combination of foreign aid and 
remittance inflow to the country. Following the ongoing research and the diverse findings, Azam and Feng (2021) conduct a research wherein they evaluate the effect of external aid on the economic growth of transition countries. They applied a cross-sectional time series technique by using the fixed-effect regression, and analysed up to thirty-seven countries in transition. They kept the countries in blocks of income categorisation, namely upper middle-income, lower-middle income, and low-income. Their statistics results show two different results - firstly they find that a combination of all the income groups with foreign aid produces a positive influence on the economic growth of these countries. However, when they examined the relationship based on the income blocks, results indicate a mixed outcome that resembles an earlier result by Rajan and Subramanian (2008). They find that foreign aid has limited effect on the low-income countries, the lower-middle income countries experience a positive effect of foreign aid and FDI on economic growth, and the upper middle-income countries experience a positive effect on growth from foreign direct investment; however, results for this income group show no positive relationship with economic growth (Azam and Feng 2021).

Researchers also note that countries with endowed natural resources more easily entice inflow of foreign capital (Africa Institute of South Africa 2009), explaining the presence of foreign investors in conflict countries such as Angola, DRC, Chad, Sudan, and Nigeria, even at the peak of conflicts. Development economists worry that, in some instances, a disproportionate amount of profits accrues to foreign investors in the region, implying more capital outflows than inflows. Critics argue that skewed profit-sharing arrangements result in a deficit for some rich countries (Baxter 2002). There is also the problem that foreign aid may at times make the recipient countries perennially dependent on foreign aid. The aid dependency ratios for sub-Saharan Africa, no matter the methods of measurement, are generally much higher than other world regions (World Bank 2006). The ratios are expected to grow even further as the region's population may likely increase by 2030 (Mills 2011). Attempts by poor countries to extricate themselves from poverty are rendered futile because of their entrenched underdevelopment and poor utilization of productive resources; poverty in these countries therefore reinforces and exacerbates a cycle of dependence on aid (Carruth and Freeman 2021; Cleaver 2005). This is why Ioan and Ioan (2016) argue that investment activity must have clearly outlined direction and attention to good infrastructure to have a meaningful effect on economic growth. It therefore 
means that the recipient country has a role to play to make foreign aid influence economic growth. Hence, the following sections provide analysis of how foreign aid influences economic development in sub-Saharan Africa by mediating foreign aid with governance effectiveness variables.

Further research on the aid and growth nexus provides further results using the Cambodian sample between 1980 and 2014. Sothan (2018) applied the auto-regression distributed lag method and included trade liberalisation and investment in the model. He finds that trade liberalisation has a short- and long-term positive influence on growth, and foreign aid shows only a positive effect on economic growth within the short-term period whilst investment shows a positive long-term influence on economic growth. Further results show that in the long-term, foreign aid showed a negative influence on economic growth and investment within the sample studied. He concludes that within the country and sample of study, it is deleterious on growth to depend on foreign aid for a longer period.

Some empirical researches have specifically focussed on examining the effect of aid on the growth of economies and governance in transition countries (Askarov and Doucouliagos 2015a; Cungu and Swinnen 2003; Askarov and Doucouliagos 2015b; Heckelman 2010). Askarov and Doucouliagos (2015a) examined the extent to which aid helps to facilitate economic growth and development in developing economies. Their results show, amongst others, that aid facilitates economic growth within the sample of countries studied. They also find that the results were robust regarding the study sample, the regression estimation, and instrumental control of endogeneity. However, they also find that the efficiency of aid does not necessarily rely on good economic policy.

In another related research, Cungu and Swinnen (2003) applied econometric analysis to examine the impact of aid on economic output and economic growth using a panel sample of countries in transition. Their econometric analysis discovers the existence of a significant and positive relationship between economic growth and receipt of foreign aid. Their further analysis indicates that the economic growth effect of aid is more pronounced under liberal economic conditions - this finding helps to quell the doubtful view of some research and is reassurance that aid can assist in the growth of developing countries.

Another group of researchers has evaluated the role of aid in strengthening governance institutions in developing countries (Askarov and Doucouliagos 2015b). Their finding does show that aid to developing 
countries helps in restoring democracies, especially regarding freedom to exercise political rights. However, although aid enhances democracy, they find no evidence that aid guarantees governance quality; instead, aid from some countries such as the USA produces an apparent negative effect on certain aspects of governance.

Another research by Heckelman (2010) evaluated the effect of aid on democracies in Eastern European countries in transition with various findings, which includes that increase in per capita aid assists in democratic reforms, and improved governance, judiciary, and election processes. Accordingly, this current research applies some governance factors as mediating variables to analyse the effect of foreign aid on economic growth of sub-Saharan African countries. In recognition of the potential influence of institutions in channelling foreign aid toward desired outcome, Babalola and Shittu (2020) evaluated the role played by institutions regarding the relationship between economic development and external aid in recipient countries of West Africa. They applied a panel and autoregressive distribution lag analysis. Within the sample of data, their result shows that external aid has no effect on economic growth of the recipient countries. In addition, when they imputed institutional variables into the equation, the institutional variables changed the outcome to a negative result. This change shows the devastating effect that institutions in sub-Saharan Africa can have on external aid received into the region for development.

Other recent empirical findings include the existence of a short- and long-term relationship between foreign aid and economic growth in subSaharan Africa (Jena and Sethi 2019a). Foreign aid has a negative effect on growth in South and South East Asia (Rao et al. 2020). Foreign aid causally affects economic growth in South Asia (Jena and Sethi 2021), and a long-term relationship exists between foreign aid inflows and economic growth (Sethi et al. 2019a). Furthermore, there is an equilibrium relationship between foreign aid and economic growth in the long- and short-term (Sethi et al. 2019b); inward remittance from abroad has a negative effect on expert growth (Jena and Sethi 2019b).

This paper finds support in the institutional theory of economic development, which raises the sentiment that even with the abundance of material and financial resources, a well-functioning institution is an important recipe for ensuring effective utilisation of resources to the benefit of economic growth (Ferreira, Fernandes, and Ratten 2019). Hence, the institutional theorists see institutions as forces that reign above individu- 
als to either thwart or lend support as a driver of political action that often blends with cognitive ethos to control material resources and systems. In this milieu, since institutions exert influence on policy issues and attendant political actions, it follows naturally that institutions catalyse access to and influence over resources (Wang, Li, and Zhao 2018). Importantly, given their supremacy, political institutions create conditions that may elevate or act as limitations to the extent to which organised groups in the society may successfully mobilize collective goods from the state institution (Amenta and Ramsey 2010). Accordingly, institutions constitute an important arm of economic growth and development given their overriding influence on the freeness of the market system, their enforcement of rights and protection of private property, which contributes to attracting international aid and investment (Chang 2011).

Accordingly, this paper differs slightly from the existing research by measuring the influence of foreign aid on sub-Saharan African economic growth by adding a nuance absent in the literature, which is moderating the influence of foreign aid on growth with three institutional variables, namely rule of law, control of corruption and governance effectiveness. Hence this paper extends existing research. The following sections present the method and results.

\section{Data and Methodology}

The paper applies the fixed effect panel multiple regression model to assess the effect of foreign aid on the economic growth of select sub-Saharan African countries. The proxy for economic growth is the GDP per capita and the proxy for foreign aid is the net official development assistance (ODA). Previous researchers on economic development have highlighted the importance of good government, such as corruption control, rule of law and effective government, in a positive economic growth (Aluko and Ibrahim 2020; De Vaal and Ebben 2011). However, previous researches have not integrated a model of foreign aid with government variables to assess GDP per capita growth. Therefore, this paper makes a novel contribution by employing government variables as a control to see how government effectiveness may support the aid received in the enhancement of economic growth. This becomes necessary because the government manages the foreign aid received.

Data on foreign aid (which is ODA as proxy), GDP per capita, and government effectiveness were derived from the World Bank archive of economic indicators and World Bank Governance Indicators respectively. 
In the main analysis of this research, data cover a sample of five subSaharan African countries over a period of four years, which constituted the panel data arrangement. The five sub-Saharan African countries are Ghana, Guinea, Gambia, Guinea-Bissau, and Equatorial Guinea.

Previous researchers have also applied fixed effect regression and panel data in economic growth research (Van Eyden et al. 2019; Gozgor, Lau, and $\mathrm{Lu}$ 2018). This paper contributes to existing models by incorporating both the foreign aid variable and government performance variables (government effectiveness, rule of law, and control of corruption) in gauging aid effectiveness on economic growth in sub-Saharan African countries. Another novelty in this research approach is that firstly, before engaging in the main analysis, the first analysis provides empirical confirmation of the research problem, which is that foreign aid to sub-Saharan Africa appears not to support positive economic development in subSaharan Africa. Equation 1 is the model for this first analysis, and the result appears in table 2.

The regression equations for the analysis appear below.

First analysis:

$$
Y=\beta_{\mathrm{o}}+\beta_{1} \chi_{1}+\varepsilon,
$$

where $Y$ is economic development (represented by GDP per capita), $\beta_{\mathrm{O}}$ is intercept or constant, $\beta_{1}$ is gradient or regression coefficient, $\chi_{1}$ is foreign aid (shortened as FAid in the analysis), and $\varepsilon$ is error (other independent variables unaccounted for in the model).

Second analysis:

$$
Y=\beta_{\mathrm{o}}+\beta_{1} \chi_{1}+\beta_{2} \chi_{2}+\beta_{3} \chi_{3}+\beta_{4} \chi_{4}+\varepsilon,
$$

where $Y$ is economic development (represented by GDP per capita), $\beta_{\mathrm{o}}$ is intercept or constant, $\beta_{1}-\beta_{4}$ are gradient or regression coefficients, $\chi_{1}$ is foreign aid (represented by FAid in the analysis), $\chi_{2}$ is governance effectiveness (represented by GovEffect in the analysis), $\chi_{3}$ is corruption control (represented by CorControl in the analysis), $\chi_{4}$ is rule of law (represented by RuleofLaw in the analysis), and $\varepsilon$ is error (other independent variables unaccounted for in the model).

\section{Definition and Measurement of Variables$$
Y-G D P \text { per Capita }
$$

GDP per capita is measured by dividing the GDP by the midyear population of a country (see https://datacatalog.worldbank.org). It is calculated in constant 2010 US\$. 


\section{$\chi_{1}-$ Foreign Aid}

Foreign aid denotes the international process of moving of money, goods or services from developed countries or international institutions to developing countries, meant for improving the welfare of the receiving country's citizens (Corporate Finance Institute 2021). This paper uses a popular foreign aid proxy referred to as Official development assistance (ODA) (OECD 2021). 'Official development assistance (ODA) is defined by the OECD Development Assistance Committee (DAC) as government aid that promotes and specifically targets the economic development and welfare of developing countries' - according to OECD, the 'DAC adopted ODA as the "gold standard" of foreign aid in 1969 and it remains the main source of financing for development aid' (OECD 2021). ODA is measured by multiplying the annual disbursement on loans to developing countries by the loan's grant component, which is calculated during the time of loan commitment (OECD 2021). Therefore, the World Bank derives a percentage of ODA from the gross national income (GNI) for each country, and this paper uses the ODA as a percentage of GNI as calculated and documented in the World Bank development data archives (see https://data.worldbank.org/indicator/DT.ODA.ALLD.CD).

\section{$\chi_{2}-$ Governance Effectiveness}

Governance effectiveness refers to a country's public service quality, the extent to which public service is free from political pressure to thwart policy and service offerings, formulation of policies, and the credibility thereof. The World Bank measures governance effectiveness using percentile ranking amongst all countries, ranging from o (lowest) to 100 (highest). Accordingly, this paper used the World Bank's measured data on governance effectiveness (see https://datacatalog.worldbank.org).

\section{$\chi_{3}$ - Corruption Control}

Corruption control level refers to the level to which public office holders use public power to pursue private advantages and/or gains. The World Bank measures corruption control using percentile ranking amongst all countries, ranging from o (lowest) to 100 (highest).

$$
\chi_{4} \text { - Rule of Law }
$$

A country's rule of law refers to the extent to which various agents adhere to and exercise confidence in the county's rules guiding the society. It goes 
TABLE 2 OLS, Using Observations 2000-2019 $(T=20)$

\begin{tabular}{lcccr}
\hline Variable & Coeff. & Std. error & $t$-ratio & $p$-value \\
\hline Const. & 2178.66 & 124.385 & 17.5154 & $<0.00001^{* * *}$ \\
FAid & -181.029 & 34.0134 & -5.3223 & $0.00005^{* * *}$ \\
\hline Mean dependent variable & 1529.038 & SD dependent variable & 167.2776 \\
Sum squared resid. & 206570.3 & SE of regression & 107.1267 \\
$R$-squared & 0.611457 & Adj. $R$-squared & 0.589872 \\
$F(1,18)$ & 28.32695 & P-value(F) & 0.000046 \\
Log-likelihood & -120.8054 & Akaike criterion & 245.6108 \\
Schwarz criterion & 247.6023 & Hannan-Quinn & 245.9996 \\
Rho & 0.451875 & Durbin-Watson & 0.560183 \\
\hline
\end{tabular}

Notes Dependent variable: GDP per Capita ssA.

further to include the credibility of business contract enforcement, credibility of law enforcement agents and the credibility of the court for seeking redress and obtaining equitable justice irrespective of social and economic status. The World Bank measures rule of law effectiveness using percentile ranking amongst all countries, ranging from o (lowest) to 100 (highest). Accordingly, this paper used the World Bank's measured data on governance effectiveness (see https://datacatalog.worldbank.org).

\section{Empirical Results and Findings}

As indicated in the above models in equation 1 and equation 2, the analysis is in two phases. The first analysis tries to appraise whether foreign aid influences economic growth in sub-Saharan Africa. The second analysis uses equation 2 to show how the introduction of governance variables assists foreign aid effectiveness for five select sub-Saharan African countries.

Table 2 shows that the relationship is significant at a $P$-value of 0.00005 . However, the relationship is negative with a coefficient of -181.029 . This shows that within the period of study, foreign aid in sub-Saharan Africa has a negative relationship with economic growth. The negative relationship in this finding, which uses the whole of sub-Saharan African foreign aid and GDP per capita data, confirms the prior findings of a negative or no relationship between foreign aid and economic growth (Adebayo and Beton Kalmaz 2020; Babalola and Shittu 2020).

This first analysis and result provide the impetus to progress to the next 
TABLE 3 Summary Statistics

\begin{tabular}{lrrrr}
\hline Variable & Mean & Median & Minimum & Maximum \\
\hline RuleofLaw & 23.0590 & 9.26000 & 4.23000 & 60.5800 \\
CorControl & 21.9325 & 13.8450 & 0.00000 & 58.2500 \\
GovEffect & 21.3655 & 15.1100 & 1.94000 & 57.7700 \\
FAid & $4.19152 e^{8}$ & $1.30640 e^{8}$ & $7.49000 e^{6}$ & $1.80387 e^{9}$ \\
GDP PCapt_Cnst & 3686.98 & 799.628 & 539.511 & 18261.1 \\
\hline Variable & Std. Dev. & C.V. & Skewness & Ex. kurtosis \\
\hline RuleofLaw & 21.2146 & 0.920015 & 0.677130 & -1.27347 \\
CorControl & 20.9349 & 0.954515 & 0.649221 & -1.11757 \\
GovEffect & 17.2773 & 0.808656 & 0.806539 & -0.564212 \\
FAid & $5.60865 e^{8}$ & 1.33809 & 1.59800 & 1.22525 \\
GDP PCapt_Cnst & 5942.06 & 1.61163 & 1.73183 & 1.28427 \\
\hline
\end{tabular}

analysis that uses data from a sample of five countries in sub-Saharan Africa to reassess the relationship between foreign aid and economic growth with the introduction of governance effectiveness variables as control variables on foreign aid. Table 3 and table 4 present the descriptive statistics and correlation coefficient.

Although table 3 is not of use in the variables relational analysis discussed, suffice it to say the core interest in table 3 is the mean, which shows the mean occurrence of each variable and the coefficient of variation, which shows the degree of dispersion during the period. Foreign aid has the highest mean occurrence during the period, followed by the GDP, rule of law, corruption, and governance effectiveness, respectively. In terms of coefficient of variation (Cv), GDP registered the highest level of dispersion during the period; this is followed by foreign aid, rule of law, corruption, and governance effectiveness, respectively. These are only descriptive characteristics of the variables and have no direct implication on the regression results discussed.

Fixed effect panel regression appears in table 5 and shows that the direction of the relationship between foreign aid and GDP per capita changes to a positive sign after the introduction of three governance variables (rule of law, corruption, and governance effectiveness) into the model.

Results from this second analysis show that when foreign aid is moderated with the three governance variables, foreign aid is positively re- 
TABLE 4 Correlation Coefficients

\begin{tabular}{lrrrrr}
\hline Variable & $(1)$ & $(2)$ & $(3)$ & $(4)$ & $(5)$ \\
\hline (1) RuleofLaw & -0.3204 & 0.6338 & 0.6316 & 0.6511 & 1.0000 \\
(2) CorControl & -0.4400 & 0.6861 & 0.6677 & 1.0000 & \\
(3) GovEffect & -0.4377 & 0.6159 & 1.0000 & & \\
(4) FAid & -0.2953 & 1.0000 & & & \\
(5) GDP & 1.0000 & & & & \\
PCAPT_CNST & & & & & \\
\hline
\end{tabular}

TABLE 5 Panel Data Regression Result for Foreign Aid and GDP in a Sample of Five Sub-Saharan African Countries

\begin{tabular}{lrrrr}
\hline Variable & Coeff. & Std. Error & $t$-ratio & $p$-value \\
\hline Const. & 2832.750 & 3034.490 & 0.9335 & 0.37059 \\
RuleofLaw & 98.177 & 127.339 & 0.7710 & 0.04569 \\
CorControl & -120.012 & 116.266 & -1.0322 & 0.02413 \\
GovEffect & -179.593 & 111.045 & -1.6173 & 0.03410 \\
FAid & 0.039 & 0.0246 & 0.1572 & 0.04779 \\
\hline$R$-squared & 0.939496 & & & \\
Adj. $R$-squared & 0.895492 & & & \\
Durbin-Watson & 2.000112 & & & \\
$P$-value $(F)$ & 0.000012 & & & \\
\hline
\end{tabular}

NOTES Model 1: Fixed-effects, using 20 observations. Included: 5 cross-sectional units. Time-series length $=4$. Dependent variable: GDP Per Capita.

lated to economic growth at a significance level of $P=0.0024$, which is far below the alpha level of 0.05. However, worthy of note is that it does seem that rule of law provides a positive significant booster to the positive influence of foreign aid on economic growth, as it has a positive regression coefficient of 98.1775 and a significant $p$-value of 0.04 . However, it is concerning that corruption and governance effectiveness have a negative effect on economic growth with negative regression coefficients of -120.012 , and -179.593, and significant $p$-values of 0.02 and 0.03 , respectively. This result also shows that weak control of corruption and weak governance have a negative relationship with economic growth, and this shows that weak governance and a low rate of corruption control can impair economic growth even in the presence of foreign aid. This second result is consistent with earlier findings, which indicate that under cer- 
TABLE 6 Robust and Diagnostic Test Summary

\begin{tabular}{ll}
\hline $\begin{array}{l}\text { Hausman Model Selection for } \\
\text { Random or Fixed Effect Test }\end{array}$ & $\begin{array}{l}P \text {-value }=0.0011 \text { (therefore, random effect model is } \\
\text { not suitable) }\end{array}$ \\
$\begin{array}{ll}\text { Correlation coefficients } \\
\text { The correlation matrix table indicates no multi- } \\
\text { collinearity }\end{array}$ \\
Adjusted $R$-squared & 0.939 \\
Autocorrelation & 0.895 \\
Dormality of residual & $=2.001$, which indicates no autocorrelation \\
& $\begin{array}{l}\text { The errors are normally distributed with a } p \text {-value }= \\
0.4010 \\
\text { The White's test for heteroskedasticity indicates there }\end{array}$ \\
& is no heteroskedasticity at a $P$-value = 0.1022
\end{tabular}

tain circumstances, foreign aid can have a positive effect on economic growth (Das and Sethi 2019; Minoiu and Reddy, 2010).

In order to conclude results arising from regression results, it is important to check how strong the linear relationship is (diagnostic test) (Shi 2013). In addition, it is also very vital to check how accurate the testing method is (robust test) (Aveh and Awunyo-Vitor 2017). This paper conducted a robust and diagnostic analysis (table 6) to improve the credibility of the results.

The Hausman Test: For random and fixed effect, suitability was conducted to determine the most appropriate model of panel regression to enhance methodological robustness. The null hypothesis is: random effect is suitable; and the alternative hypothesis: fixed effect is suitable. Since the $P$-value is $=0.0011$, the null hypothesis of random effect suitability was rejected (therefore, random effect is not appropriate). Hence, fixed effect is used. In addition, table 4 presents the correlation matrix table and indicates absence of multicollinearity. Furthermore, the diagnostic tests for the strength of the regression were conducted; the most acknowledged measure of strength of relationship in the literature is the standard error (SE) of regression (Misra, Zimba, and Gasparyan 2021; Walter 2002), which experts also refer to as standard error of estimate. The small standard error of this test being 0.024 suggests that predicted variable lies very close to the regression line - which is a reliable test of regression precision. This is confirmed by the further diagnostics of $R$-squared at $93 \%$ and adjusted $R$-squared at $89 \%$; the Durbin-Watson test of autocorrelation is at a value of $=2.0001$ showing absence of autocorrelation. In 
addition, the normality test and heteroscedasticity tests values of 0.4010 and 0.102 indicate that errors are normally distributed and that there is no heteroskedasticity.

\section{Conclusion and Policy Implication}

This paper aimed to analyse the effect of foreign aid on economic development in sub-Saharan Africa. Prior researchers have dwelt more on exogenous variables, but this paper contributes differently by adding a new model, which integrates endogenous variables, namely the government effectiveness variables as control variables to the foreign aid variable. The analyses were in two separate phases; from the first analysis, findings show a negative link between external aid and economic growth represented by GDP per capita in sub-Saharan Africa. A second analysis, which applied the panel fixed effect multiple regression approach, indicates that indeed, foreign aid does have a positive and significant effect on economic growth. However, this positive relationship showed up after the inclusion of governance variables, namely rule of law, corruption, and governance effectiveness into the equation as intervening variables. In the second analysis, findings indicate that the rule of law provides a positive boost to foreign aid and GDP growth. In contrast, an increasing level of corruption and weakening governance showed a negative relationship with economic growth. This finding corroborates previous findings on the positive relationship between foreign aid and growth (such as Das and Sethi 2019; Minoiu and Reddy 2010). However, the difference between this paper's findings and previous findings is that foreign aid became positively significant only when governance variables were added - thus adding a nuance to this paper and signifying the importance of institutional or governance variables in boosting aid effectiveness in sub-Saharan Africa. Hence, this second result indicates an important policy implication on the need to bridle corruption and strengthen the rule of law and government effectiveness institutions to enable foreign aid to yield the dividend of economic growth in sub-Saharan Africa.

Relying on the findings, the paper recommends the need for economic policy makers to improve the state institutional control mechanisms to reduce the level of corruption in the governance sector as one of the strategic economic growth policy measures. This is because bureaucrats are in charge of and provide policies and operations for investing the proceeds of foreign aid, and this needs to be done in an effective and accountable manner. Another recommendation for economic policy mak- 
ers' attention is the dire need for strengthening the rule of law and government effectiveness as this research shows that weakness in the rule of law and government effectiveness has the propensity to retard the positive effect of foreign aid on economic growth. Furthermore, the existing subregional trade blocs in the region need strengthening to promote effective use of the region's natural resources to promote economic growth with the assistance of foreign aid. Therefore, economic policy makers should also consider effective apparatus to turn the weakening trajectory of government effectiveness toward a positive trajectory.

The limitation of this paper lies in its focus on data from sub-Saharan Africa and on limited time coverage, mainly due to availability of data for the sample. However, this limitation is an opportunity for further research to explore this important growth and development concept further. Accordingly, the paper provides an avenue for future researchers to extend this research more by conducting regional analysis that may use data from western, southern, and eastern African countries to assess how regional variables might affect the result of the aid's effect on economic growth. In addition, such future research should strive to include all governance variables, which may reveal more results on additional governance variables that have the propensity to assist foreign aid to grow or retard economic growth.

\section{References}

Adebayo, T. S., and D. Beton Kalmaz. 2020. 'Ongoing Debate between Foreign Aid and Economic Growth in Nigeria: A Wavelet Analysis.' Social Science Quarterly 101 (5): 2032-51.

Africa Institute of South Africa. 2009. Africa at a Glance: Facts and Figures 2008-2009. Pretoria: Africa Institute of South Africa.

Aluko, O. A., and M. Ibrahim. 2020. 'Institutions and the Financial Development-Economic Growth Nexus in Sub-Saharan Africa.' Economic Notes 49 (3): e12163. https://doi.org/10.1111/ecno.12163.

Amenta, E., and K. M. Ramsey. 2010. 'Institutional Theory'. In Handbook of Politics: State and Society in Global Perspective, edited by K. T. Leicht and J. C. Jenkins, 15-39. New York: Springer.

Askarov, Z., and H. Doucouliagos. 2015a. 'Development Aid and Growth in Transition Countries.' World Development 66:383-99.

- 2015b. 'Aid and Institutions in Transition Economies.' European Journal of Political Economy 38:55-70.

Aveh, F. K., and D. Awunyo-Vitor. 2017. 'Firm-Specific Determinants of Stock Prices in an Emerging Capital Market: Evidence from Ghana 
Stock Exchange.' Cogent Economics \& Finance 5 (1). https://www.doi.org /10.1080/23322039.2017.1339385.

Azam, M., and Y. Feng. 2021. 'Does Foreign Aid Stimulate Economic Growth in Developing Countries? Further Evidence in Both Aggregate and Disaggregated Samples.' Quality \& Quantity. https://link.springer .com/article/10.1007/s11135-021-01143-5.

Babalola, S., and W. Shittu. 2020. 'Foreign Aid and Economic Growth in West Africa: Examining the Roles of Institutions.' International Economic Journal 34 (3): 534-52.

Baxter, J. 2002. 'Another Africa is Possible.' Africa Recovery 16 (1): 18-9.

Bhagwati, J. N. 2010. 'Banned Aid: Why International Assistance Does Not Alleviate Poverty'. Foreign Affairs 89 (1): 120-5.

Carruth, L., and S. Freeman. 2021. 'Aid or Exploitation? Food-for-Work, Cash-for-Work, and the Production of Beneficiary-Workers in Ethiopia and Haiti.' World Development 140. https://doi.org/10.1016/j .worlddev.2020.105283.

Cleaver, F. 2005. 'The Inequality of Social Capital and the Reproduction of Chronic Poverty.' World Development 33 (6): 893-906.

Chang, H. J. 2011. 'Institutions and Economic Development: Theory, Policy and History'. Journal of Institutional Economics 7 (4): 473-98.

Corporate Finance Institute. 2021. 'Foreign Aid: The Voluntary Movement of Capital from One Country to Another.' https://corporatefinance institute.com/resources/knowledge/economics/foreign-aid/.

Cungu, A., and J. Swinnen. 2003. 'The Impact of Aid on Economic Growth in Transition Economies: An Empirical Study.' Licos Discussion Paper 128, Katholieke Universiteit Leuven, Leuven.

Das, A., and N. Sethi. 2019. 'Effect of Foreign Direct Investment, Remittances, and Foreign Aid on Economic Growth: Evidence from two Emerging South Asian Economies.' Journal of Public Affairs 20. https://onlinelibrary.wiley.com/doi/abs/10.1002/pa.2043.

De Vaal, A., and W. Ebben. 2011. 'Institutions and the Relation between Corruption and Economic Growth.' Review of Development Economics 15 (1): 108-23.

Easterly, W. 2002. The Elusive Quest for Growth: Economists' Adventures and Misadventures in the Tropics. Cambridge, m A: Mi T Press.

Ferreira, J. J., C. Fernandes, and V. Ratten. 2019. 'The Effects of Technology Transfers and Institutional Factors on Economic Growth: Evidence from Europe and Oceania.' The Journal of Technology Transfer 44 (5): 1505-28.

Gozgor, G., C. K. M. Lau, and Z. Lu. 2018. 'Energy Consumption and Economic Growth: New Evidence from the oECD Countries.' Energy 153:27-34. 
Grabowski, R. 2006. 'Political Development, Agriculture, and Ethnic Divisions: An African Perspective.' African Development Review 18 (2): 163-82.

Heckelman, J. C. 2010. 'Aid and Democratization in the Transition Economies.' Kyklos 63 (4): 558-79.

Ioan, C. A., and G. Ioan. 2016. 'An Equilibrium Model for the Romanian Economy' The Journal of Accounting and Management 6 (2): 41-75.

Ismail, K. M. 2020. 'Impact of Foreign Aid on Economic Growth in Tanzania.' Master's dissertation, The University of Dodoma.

Jena, N. R., and N. Sethi. 2019a. 'Foreign Aid and Economic Growth in SubSaharan Africa.' African Journal of Economic and Management Studies 11 (1): 147-68.

- 2019b. 'Does Inward Remittance Lead to Export Performance in South Asian Countries?' International Journal of Social Economics 47 (2): $145-72$.

- 2021. 'Foreign Capital and Growth Nexus Revisited: Empirical Evidence from South Asian Countries. Transnational Corporation Review 13 (3): 269-92.

Kilby, C., and A. Dreher. 2010. 'The Impact of Aid on Growth Revisited: Do Donor Motives Matter?' Economics Letters 107 (3): 338-40.

Lal, D., and S. Rajapatirana. 2007. 'The Triumph of Hope over Experience: A Marshall Plan for Sub-Saharan Africa?' American Enterprise Institute for Public Research 2:1-7.

Mallik, G. 2008. 'Foreign Aid and Economic Growth: A Cointegration Analysis of the Six Poorest African Countries.' Economic Analysis \& Policy 38 (2): 251-6o.

Mbah, S., and D. Amassoma. 2014. 'The Linkage between Foreign Aid and Economic Growth in Nigeria.' International Journal of Economic Practices and Theories 4 (6): 1007-17.

Mills, G. 2011. 'Urban Youth Can Save Africa Or Sink It.' Sunday Times, 9 October.

Minoiu, C., and S. G. Reddy. 2010. 'Development Aid and Economic Growth: A Positive Long-Run Relation.' The Quarterly Review of Economics and Finance 50 (1): 27-39.

Misra, D. P., O. Zimba, and A. Y. Gasparyan. 2021. 'Statistical Data Presentation: A Primer for Rheumatology Researchers.' Rheumatology International 41 (1): 43-55.

OECD. 2014. 'ODA Receipts and Selected Indicators for Developing Countries and Territories.' http://www.oecd.org/dac/stats/ statisticsonresourceflowstodevelopingcountries.htp.

_. 2021. 'Official Development Assistance.' https://data.oecd.org/oda /net-oda.htm. 
Omoteso, K., and H. I. Mobolaji. 2014. 'Corruption, Governance and Economic Growth in Sub-Saharan Africa: A Need for the Prioritisation of Reform Policies.' Social Responsibility Journal 10 (2): 316-30.

Rajan, R. G., and A. Subramanian. 2008. 'Aid and Growth: What Does the Cross-Country Evidence Really Show?' The Review of Economics and Statistics 90 (4): 643-65.

Rao, D. T., N. Sethi, D. P. Dash, and P. Bhujabal, 2020. 'Foreign Aid, FDI and Economic Growth in South-East Asia and South Asia.' Global Business Review. https://doi.org/10.1177/0972150919890957.

Sethi N., P. Bhujabal, A. Das, and S. Sucharita. 2019a. 'Foreign Aid and Growth Nexus: Empirical Evidence from India and Sri Lanka.' Economic Analysis and Policy 64:1-12.

- 2019b. 'Does Foreign Aid Act as an Instrument of Economic Growth in India and Sri Lanka?' Jurnal Ekonomi Malaysia 53 (2): 319.

Shi, Y. 2013. 'A New Diagnostic Test for Regression.' Master thesis, The University of Western Ontario.

Sothan, S. 2018. 'Foreign Aid and Economic Growth: Evidence from Cambodia.' Journal of International Trade \& Economic Development 27 (2): 168-83.

UND P. 2021. Graduation of African Least Developed Countries. https://www .africa.undp.org/content/rba/en/home/library/reports/graduation-ofafrican-least-developed-countries-ldcs-emergin.html.

Van Eyden, R., M. Difeto, R. Gupta, and M. E. Wohar. 2019. 'Oil Price Volatility and Economic Growth: Evidence from Advanced Economies Using More than a Century's Data.' Applied Energy 233:612-21.

Walter, S. D. 2002. 'Properties of the Summary Receiver Operating Characteristic (s roc) Curve for Diagnostic Test Data.' Statistics in Medicine 21 (9): 1237-56.

Wang, S., J. Li, and D. Zhao. 2018. 'Institutional Pressures and Environmental Management Practices: The Moderating Effects of Environmental Commitment and Resource Availability.' Business Strategy and the Environment 27 (1): 52-69.

World Bank. 2006. World Development Indicators 2006. Washington, DC: The World Bank.

Žižmond, E., and M. Novak. 2006. 'Impact of Price-Deregulation on Market Outcomes: The Case of Chimney Sweep Services in Slovenia.' Prague Economic Papers 15 (4): 350-63. 
The Digital Transformation of Public Authorities: Creating an Agile Structure and Streamlining Government Presence Using the Example of Tax Offices

Daniel Simon Schaebs

Pegaso International, Malta

info@daniel-schaebs.de

In the face of unforeseen events and the ongoing digital transformation, public authorities need to find agile concepts to meet the challenges ahead. The requirements for agile action are defined and explained for a tax office and its adjustments. Modern information and communication technologies, decentralised work and leadership and contemporary e-government concepts can lead to organisational advantages and higher efficiency by breaking down strong hierarchical structures and creating an agile environment. An analysis model for examining the supply efficiency of tax offices, taking into account the area of responsibility and the inhabitants to be served, is presented. A median-oriented value was defined as a 'realistically achievable minimum' for supply and a '(minimum) relation curve' illustrates the target. The advantages of the digital transformation can be used by digital and agile tax offices because they create opportunities to streamline the presence of the authorities and use potentials to increase the effectiveness of service provision.

Key Words: agile authorities, tax administration, tax offices, digitisation, digital transformation JEL Classification: $\mathrm{H} 21, \mathrm{H} 71$

(cc) BY.SA https://doi.org/10.26493/1854-6935.19.327-342

\section{Introduction}

Authorities increasingly have to prove themselves in dealing with unforeseen events, such as the financial or refugee crisis and, currently, the coronavirus pandemic. The latter forced the administrations to make digital interaction with citizens possible within a short period of time because contact restrictions and protective measures did not permit visits to the authorities. This forced experiment seems to have succeeded in large parts of the administrations. For public administrations, nothing less than a paradigm shift due to digitisation is imminent in many 
areas. Analogue processes will be supplemented, changed or even replaced by digital solutions. At the same time, the coronavirus pandemic has put the working environment in government agencies to the test and changed it. Location-flexible, mobile working from home is already a widespread method used almost across the board in the various tax administrations in Europe. The German Federal Ministry of Finance notes that this strengthens employees' personal responsibility and motivation, establishes additional digitally oriented workflows and can streamline processes (Deutscher Bundestag 2020, 4).

Overall, however, there are still considerable deficits in the use of digital technologies in the public sector in many European countries. Germany, for example, ranked only 12 th out of $28 \mathrm{EU}$ countries in the Digital European Society Index (DESI) in 2020 and in the UN E-Government Survey (EGDI) 2020, it lost 13 places (rank 25) compared with the year 2018 (rank 12). If the economic performance of the countries were included, Germany would be in an even worse position (Schaebs 2020). Positive examples in Europe are to be found not only among the Baltic central states; Austria and Belgium also stand out here despite their federalist state structure. An economy as large as Germany, with a very high per capita income, should be much better at digitising its administration because it has the necessary possibilities for investments, tax revenue and procurement structures. For the purposes of this paper, the necessary investments are assumed to be possible in principle and are not examined in detail.

A more digital administration would also improve participation opportunities for citizens and thus promote democracy (Lenz, Witte, and Saebisch 2021, 7). According to a survey, 53\% of citizens in Germany believe that the offices and authorities will revert to their old patterns and remain analogous once the pandemic is over (Berg 2021, 12). So this work aims to contribute to supporting the digital transformation of authorities in tax administration by identifying structural changes that can increase agility. It will also examine the number of authorities necessary and so suggest how the structural organisation of tax offices can be streamlined and whether there are limits to this endeavour.

The following research questions can be formulated in this regard:

$\mathrm{RQ1}$ What changes to the structure would be necessary for a tax office to be able to act more agilely in the face of the challenges in digitisation? 
RQ2 What potentials for streamlining the presence of the tax offices do exist, taking into account the responsible area and inhabitants to be served, and what are the limits?

The paper is divided into six sections. After this introduction, the second section describes the determinants for an agile organisation of authorities. The third section presents the methodology used within this thesis to answer the research questions. The fourth section provides answers to research question 1 . The fifth section presents potentials from streamlining the presence of authorities and limits and so provides answers to research question 2. The paper ends with a conclusion in the sixth section.

\section{Agile Organisational Structure for Authorities}

No fixed definition of agility has yet emerged in the literature. In terms of management, for example, agile action is seen as the ability to better identify key risks, take precautions, and act quickly with clear ideas about development directions (Lévesque and Vonhof 2018, 18). Agile action would also be when organisations try out, look at and adapt, and react as closely and appropriately as possible to the actual situation with all its changes (Lévesque 2018, 164).

However, this mindset or attitude requires suitable framework conditions in the organisation and at management level (Vonhof 2018, 172). Many of the existing explanatory approaches in the literature have in common that it can be spoken of agile when, in the case of change requirements, the action is characterised by adaptability, flexibility, initiative, anticipation and dynamism. Nevertheless, customer centricity and the ability to organise oneself could also be used as benchmarks for management (Steuck 2019, 13). This is likely to be significant in view of the challenges of digitising tax administration and citizens' expectations of a functioning, digital state.

Agile forms of organisation not only emphasise the use of modern digital tools, but also call for a very fundamental change in work culture (Michl and Steinbrecher 2018, 27) that develops thinking in fixed processes, systems and departments into designing adapted organisation with network-like structures (Lévesque and Michl 2018, 50). In business enterprises, market conditions and customer demands have always required constant adaptability. To this day, administrations in Germany work almost independently of market's needs, but much more accord- 
ing to the system described by Max Weber of strong written rules, standardised work processes and work flows that exist independent of people, according to clear hierarchies and with a functional objective. Proponents see this as the basis for certainty, consistency, continuity, stability of the organisation and facilitated coordination.

However, like all social systems, administration cannot resist the pressure to adapt and change (Steuck 2019, 1), especially since the tax administration in particular must also establish an eye-level status with administrations outside Germany due to cross-border issues. An immobile and inflexible administration is poorly positioned for change processes (Steuck 2019, 31), because instead of a decentralised form of organisation, a typical relationship of superordination and subordination binds the processes of responsibility, decision-making and design with the managers (Steuck 2019, 32). If it were possible to increase the scope for action for employees in the sense of more personal initiative and responsibility, and at the same time to reduce the need for control on the part of managers, the degree of self-organisation of the individual job could increase and thus enable agile approaches (Steuck 2019, 32). In an empirical study within the federal administration in Germany, Steuck was able to identify the main obstacles to establishing an agile culture within government agencies. According to this study, rigid budgetary regulations (63\%), fear of change (58\%), hierarchical thinking and structure $(54 \%)$, the need for control (50\%), service and collective bargaining law (46\%) and, among other things, complex decision-making and approval processes $(38 \%)$ have a negative impact on the introduction of agile concepts (Steuck 2019, 151).

\section{Methodology}

A systematic literature review (SLR) was conducted with regard to remote work and leadership concepts, supporting organisational or efficiency advantages through modern IC $\mathrm{T}$ and current e-government concepts in order to be able to describe the model of digital and agile tax offices. In this way the extension of already existing assumptions for agile public authorities led to answers for RQ1 with regard to the tax offices.

For answering RQ2, the literature was examined and evaluated for previous models or assumptions. By updating an existing analytical model for the study of the supply efficiency of tax offices, taking into account the responsible area and the inhabitants to be served, statements and values could be updated. For this purpose, data was newly collected. 


\section{Agile and Digital Tax Offices}

A report by the Scientific Advisory Board at the Federal Ministry for Economic Affairs and Energy (Bundesministerium für Wirtschaft und Energie) states that the backlog in digitisation is due to various forms of organisational failure (Bundesministerium für Wirtschaft und Energie 2021, 24). It remains the duty of the state to digitise its administration as well as the interfaces with citizens as far as possible and to use the savings in bureaucracy, acceleration, time and tax money (Lohmann 2018, 17). This digital transformation in the tax administration must start at various points, which will be presented individually below and will be necessary for a tax office to be able to act more agilely in the face of the challenges in digitisation.

\section{STRUCTURAL ADJUSTMENTS}

The structure of the tax administration and the tasks of a tax office are defined by law in Germany and cannot be easily changed due to the federal division. In other countries with a centralised tax administration, the tasks and structure can be more easily adapted by the government, as there is no resistance from individual administrative levels. Tax offices are generally divided into departments, which comprise several areas of work as the smallest organisational units and where decisions are made (Schaebs forthcoming). Thus, in almost every tax office there are postal, business, appeal, tax audit, enforcement and wage tax offices. In practice, however, the rigid organisational structure within a Land means that tax offices should remain comparable from the point of view of the higher authorities, at least to be able to compare quantitative success factors, key personnel figures and approaches in cost and performance accounting. Change processes are therefore not sufficiently supported or even prevented in the sub-authorities.

This lack of willingness to change is also evident in the switch to alternating teleworking, mobile working/home office and co-working formats. Staff management and the current departmental organisation must be rethought. Up to now, the work areas of a department have been physically close to each other, so that managers can fulfil their tasks by means of control and management instruments directly on site. However, these tasks, as well as care and supervision, could also be realised with the help of modern leadership approaches, for example through leadership at a distance (remote leadership), even without the common location as a link (Hermann, Hünecke, and Rohrberg 2012). 
A 2020 study at the Zurich University of Applied Sciences (zHAw) analysed the consequences of distance management during the coronavirus pandemic within the university administration. It generally showed that the organisation was able to cope very well with the changeover (Zirkler, Scheidegger, and Bargetzi 2020, 4), although 'the importance of hierarchical line management' decreased and leadership impulses shifted in favour of self-management competences. Among other things, the authors suggest that the safe use of digital tools should be learned and the 'toolbox' constantly expanded. Furthermore, the technical infrastructure would have to be expanded and distance leadership anchored in personnel concepts. From hierarchical line management, they demand more courage for distributed leadership in the team as well as for empowerment of the employees in the sense of self-leadership.

Even though the ad-hoc conversion was an extreme situation, the findings can be transferred to distance management in the tax offices. A large part of the employees in the tax offices work in the field, anyway (including tax audits, special vat audits, external wage tax audits, enforcers, experts), so that those department heads have long since developed appropriate methods of remote leadership. Nevertheless, the state revenue administration should recognise the potentials, promote the extensive use of remote leadership and meet the challenges through continuous training offers and internal administrative evaluations.

A separation into front and back office with simultaneous outsourcing of the back office is also advocated by experts, whereby personal counselling and basic services on site for citizens are retained in the front office. Experts are available in the back office and standardised processes are concentrated.

A tax office of the future could, at least in part, consist of purely digital subject areas, in which various employees have a fixed workstation in the home office only, but are considered virtually as a work area and are combined into completely digital subject areas. The hybrid form of work that has prevailed up to now, consisting of mobile work, semi-mobile work and office-based work, would be effectively further developed in this respect. The current hybrid forms of work, in which employees have a workplace both in the tax office and in the home office (teleworking), require a double technical infrastructure and changing assignments. Spatial and technical efficiency advantages could only be achieved if the principle that every employee has a personal workstation in the office building is abandoned in the sense of digital transformation. In this way, a change 
towards an agile work culture could be achieved by dissolving strictly hierarchical structures and demanding strong self-organisation, which in turn also promotes agile thinking and action among employees. The centralisation of tasks at certain tax offices could also increase the possibilities for savings by allowing employees to build up specialisation competences by processing similar procedures and by achieving economies of scale and synergy effects. The extent to which fewer departments need to be formed and thus fewer managers are needed also depends on the structure, especially the scope of tasks and the number of taxpayers to be administered.

\section{Digital Taxation Procedure and Automation-Friendly Laws}

The implementation of fully computerised processing procedures in tax administration, especially in the tax offices, is the prerequisite for modern e-government offerings in tax administration and corresponding added value for citizens. Numerous proposals for the use of specific digital technologies, such as machine learning and artificial intelligence in the taxation process have already been made in the literature. The exchange of data at $\mathrm{EU}$ level has been expanded and supplemented by information obligations for certain industries as well as operators of electronic platforms. Therefore, the amount of data to be processed by the tax administration will grow exponentially in the future. The mass data to be processed will present the tax authorities with considerable challenges. Without sufficient technical support, they will not be able to cope with this task. Rather, the tax administrations will have to relieve the - prospectively reduced - staff of routine tasks by means of electronic systems in order to deploy them in a targeted manner where technology cannot (yet) provide support. One model for the full-scale digitisation of the taxation process was developed by Peuthert et al. (2021). It connects the existing and still required data for intelligent use and shows the advantages for the tax offices.

In order to be able to use more innovative technologies in the taxation process, it will be crucial, among other things, for tax laws to capture the reality of life, but also to be automation-friendly and digitally suitable. Interdisciplinary cooperation between IT experts, people from professional practice and lawyers is therefore needed. A digital taxation process and the successful use of IC T in the taxation process can help administrations to respond agilely, that means more flexibly and dynamically, to challenges in the future. This has been shown, for example, in 
the digital application and payment of coronavirus aid by the German administration.

\section{Digital Culture and Understanding}

If analogue and digital processing options exist in parallel, there is a danger that employees will shy away from the still unknown, digital path out of habit or simplicity. In this respect, the emergence of a 'digital culture' in the administration would be desirable, in which the digital solution should be preferred in the sense of a 'digital-first approach'. Digitisation will change professions and individual activities. The administration must proactively lead the way here and empower its employees for the digital transformation. For the tax administration, Peuthert and Schaebs (forthcoming) have described a modular and consecutive qualification with regard to the digital transformation. The focus is on learning a strong application methodology in order to be able to adapt agilely to the complex, rapidly changing tax law at any time. At the same time, networked thinking in the sense of an agile process understanding instead of a silo approach is to be strengthened. Learning is stretched and enables a deeper understanding and the emergence of digital soft skills. Furthermore, all approaches should be accompanied by appropriate change management tools and people should receive training that also enables them to acquire future and digital skills.

\section{Potentials from Streamlining the Presence of Authorities and Limits}

In the tax administration, the enormous potential of digital administrative processes to increase efficiency could principally benefit both citizens and the administration to the same extent (Schaebs forthcoming). At the same time, the question arises as to whether the reduction in administrative workload, for example the elimination of simpler tasks and the acceleration of processing procedures, will lead to a reduction in the number of employees or infrastructure required. However, it is already certain that the changes in the organisation of structures and processes due to the enormous increase in mobile work concepts and implementation of IC T will make some of the office space held by public authorities obsolete. Currently, there is still a tendency for tax offices to be located as close as possible to citizens. A relocation to rural areas, a closure of tax offices or downsizing of buildings is not yet taking place. However, recently Kulicke $(2020,58)$ came to the conclusion that it would not be 
problematic if tax offices withdrew from some areas. According to the experts, a stationary presence could rather be limited to personal counselling centres. A citizen survey for 2019 and 2020 in Germany (Freistaat Sachsen 2021) reveals the attitudes of citizens. According to the survey, only $13 \%$ of respondents seek contact with their local tax office in person. Contact is made by telephone by $32 \%$, by letter by $7 \%$, by email by $24 \%$ and via the online channel 'My Elster' by $21 \%$. Overall, $68 \%$ said they had not had any personal on-site contact with their tax office within the last three years. The locally poorer accessibility (poorer connection by public transport or further distance) does not lead to dissatisfaction among the interviewees and is thus of below-average relevance. Similar results are also provided by the survey about different living situations in 2019 from the German Federal Statistical Office for the area of tax returns (Statistisches Bundesamt 2019). In the following, an analysis of the supply of the area and inhabitants will be used to examine the potential for reducing the infrastructure to be provided and to find an optimal ratio considering the survey results.

\section{Streamlining the Infrastructure and Optimisation of Supply Efficiency}

In order to be able to analyse a streamlining of the structures, the number of existing tax offices must be compared over a period of time and the area served and the number of inhabitants or population density served must be included. Such an analysis was carried out under the leadership of Prof. Dr. Joachim Hesse for the tax administration in Germany in the 2006 report on the reform of the sovereign administration (Hesse, Götz, and Schubert 2007, 77). For this purpose, the values for the year 2021 can be newly collected and compared.

Table 1 provides an overview of the federal states selected by Hesse, Götz, and Schubert (2007), each of which has its own tax administration in Germany. At the same time, the changes in the number of tax offices, the population size and the supply situation are visible. The supply situation is measured in two quantities, on the one hand how much area each tax office is responsible for and on the other hand how many inhabitants each tax office is responsible for. This results in an observation period of 15 years, during which mainly I c cooperation and automation within the tax administration were built up. The last five years have significantly improved the digitisation of the taxation process with the introduction of legal foundations and the use of digital procedures. Therefore, in the 
TABLE 1 Changes and Developments in the Tax Administrations of the Länder

\begin{tabular}{lrrrrrr}
\hline Länder & Year & $(1)$ & $(2)$ & $(3)$ & $(4)$ & $(5)$ \\
\hline North Rhine-Westphalia $\left(34.112 \mathrm{~km}^{2}\right)$ & 2006 & 18.1 & 137 & 531 & 132,117 & 249 \\
& 2021 & 17.9 & 137 & 525 & 130,657 & 249 \\
\hline Bavaria $\left(70.542 \mathrm{~km}^{2}\right)$ & 2006 & 12.4 & 82 & 176 & 151,220 & 860 \\
& 2021 & 13.1 & 76 & 186 & 172,368 & 928 \\
\hline Baden-Württemberg $\left(35.748 \mathrm{~km}^{2}\right)$ & 2006 & 10.7 & 65 & 299 & 164,615 & 550 \\
& 2021 & 11.1 & 65 & 311 & 170,769 & 550 \\
\hline Lower Saxony $\left(47.710 \mathrm{~km}^{2}\right)$ & 2006 & 8 & 68 & 168 & 117,647 & 702 \\
& 2021 & 8 & 63 & 168 & 126,984 & 757 \\
\hline Rhineland-Palatinate $\left(19.858 \mathrm{~km}^{2}\right)$ & 2006 & 4.1 & 26 & 206 & 157,692 & 764 \\
& 2021 & 4.1 & 22 & 206 & 186,364 & 903 \\
\hline Schleswig-Holstein $\left(15.801 \mathrm{~km}^{2}\right)$ & 2006 & 2.8 & 18 & 177 & 155,556 & 878 \\
& 2021 & 2.9 & 17 & 184 & 170,588 & 929 \\
\hline Brandenburg $\left(29.654 \mathrm{~km}^{2}\right)$ & 2006 & 2.5 & 17 & 84 & 147,059 & 1744 \\
& 2021 & 2.5 & 13 & 84 & 192,308 & 2281 \\
\hline Saxony-Anhalt $\left(20.457 \mathrm{~km}^{2}\right)$ & 2006 & 2.5 & 21 & 122 & 119,048 & 974 \\
& 2021 & 2.2 & 14 & 108 & 157,143 & 1461 \\
\hline
\end{tabular}

NOTES Column headings are as follows: (1) inhabitants in mio., (2) tax offices (abs.), (3) population density (inh. $/ \mathrm{km}^{2}$ ), (4) inhabitants per tax office, (5) area in $\mathrm{km}^{2}$ per tax office. Based on data from Statistisches Bundesamt (https://www.destatis.de) and Bundeszentralamt für Steuern (https://www.bzst.de).

following, an improvement in the supply situation is assumed if, in view of the developments in automation and digitisation, the efficiency potentials in terms of area and population are exploited by the tax offices in the best possible way.

The states of Saxony-Anhalt (33.33\%) and Brandenburg (25.53\%), as well as Rhineland-Palatinate (15.38\%), have implemented the streamlining of their structures best over the period. Baden-Württemberg and North Rhine-Westphalia have not reduced the absolute number of tax offices. The other German Länder have only made a small reduction, which is below average in view of the long period and the existing potential. However, some of the federal states had already significantly reduced the number of tax offices by 2006, for example Baden-Württemberg (Hesse, Götz, and Schubert 2007, 44).

Figure 1 graphically illustrates the developments in the respective tax 


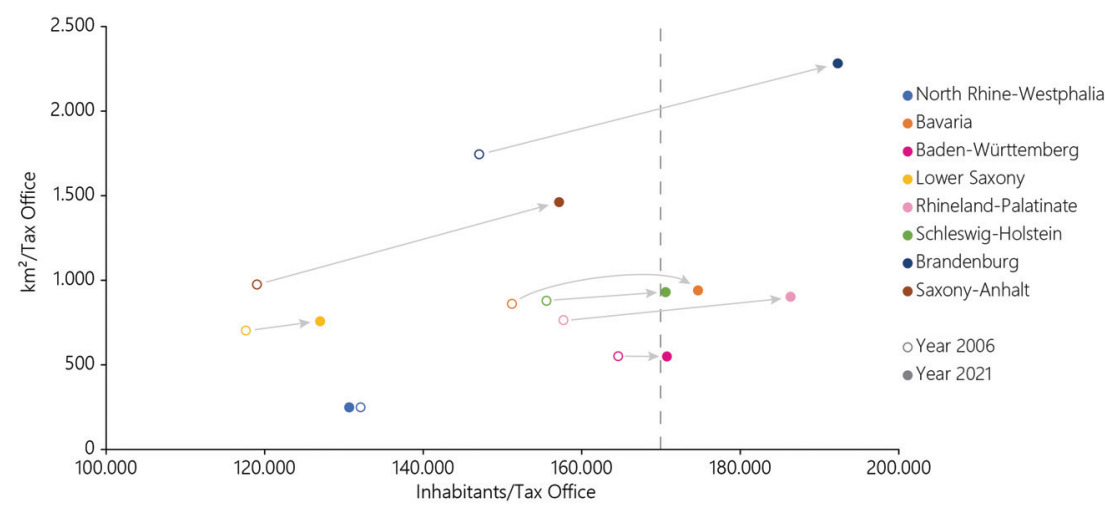

FIGURE 1 Supply Range per Area and per Inhabitant from 2006 to 2021 per Tax Office

administrations of the Länder in the period under consideration from 2006 to 2021. According to this, the majority of the countries were able to improve the effectiveness of supply compared to 2006 by reducing the number of tax offices; in 2021, more area per tax office ( $y$-axis/ordinate) and more inhabitants per tax office ( $x$-axis/abscissa) can be supplied. This could be linked to automation and digitisation, because these speed up work processes and thus increase the efficiency of the tax offices. An equal number of employees could thus take on more tax cases and concentrate on core tasks.

Only two federal states have not used the efficiency potential at all. Baden-Württemberg has not changed the number of tax offices, but since the number of inhabitants has increased, this results in a slightly better supply situation (tax office per inhabitant). North Rhine-Westphalia has a slightly lower number of inhabitants, but the number of tax offices has remained the same, resulting in a slightly worse supply situation (tax office per inhabitant). Two Länder (Lower Saxony, Schleswig-Holstein) show only a slight improvement, due to only a slight reduction in the number of tax offices with a simultaneous change in the number of inhabitants.

The dotted line is the result of calculating the median number of inhabitants served by each tax office. Based on the result, it can be assumed that each tax office would basically be able to serve 170,000 inhabitants (median). This median is considered a 'realistically achievable minimum' in the following analysis and thus forms a lower threshold.

Looking exclusively at the situation in 2021, figure 2 shows the relationship between the area served per tax office ( $y$-axis/ordinate) and the existing population density ( $x$-axis/abscissa). It shows the typical tension: 


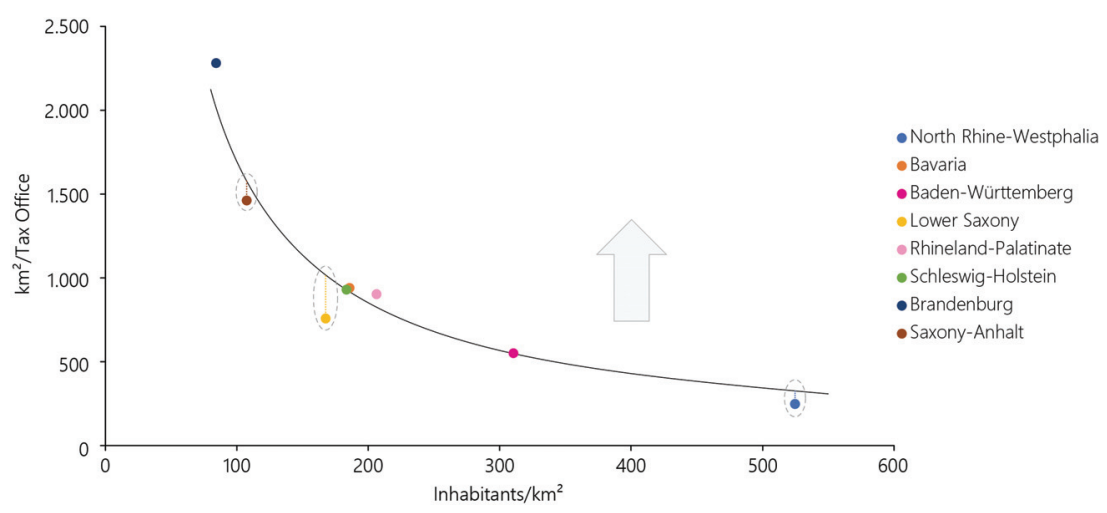

FIGURE 2 Relation Curve for Determining Minimum Coverage of Area and Population Density

with a low population density, a tax office has to cover more area, with increasing population density, the individual unit has to cover less area.

Taking into account the median determined above, a '(minimum) relation curve' can be calculated. Länder that lie on or above this curve have already been able to implement an appropriate level of efficiency. This means in these states that each tax office services at least 170,000 inhabitants (Bavaria, Baden-Württemberg, Brandenburg, RhinelandPalatinate, Schleswig-Holstein). All of the states that are below the trend curve are not exploiting their potential and can optimise the supply (Lower Saxony, North Rhine-Westphalia, Saxony-Anhalt). The large arrow symbolises that this can only be done by supplying more inhabitants, which automatically results in a larger area.

Taking into account the value of 170,000 inhabitants to be served per tax office, which is defined as a 'realistically achievable minimum' on the basis of the median, for the population figures of the Länder in 2021, results in a new number of necessary tax offices. This can be compared with the existing tax offices in 2021. In this way it can be determined that the savings potentials exist for Saxony-Anhalt ( 1 tax office), Lower Saxony ( 16 tax offices), and North Rhine-Westphalia (32 tax offices). Only when the number of tax offices in these states is reduced accordingly, would they be on the curve and the supply situation would be on trend in relation to the other states.

\section{ORGANISATIONAL AND LEGAL LIMITS}

Since the tax administration, at least in Germany, does not provide basic services for the citizens, i.e. it is not part of the services of general interest, 
but is a pure sovereign administration, the government is relatively free to determine the scope and the structures. At the same time, however, there is also a claim of the people or the general public to a functional capability and the fundamental existence of state structures in the sense of a functioning tax enforcement. If, despite the use of IC $\mathrm{T}$ and possible smaller contact points in the cities, neither the digital nor the physical accessibility were given, for example, without opening or service hours for information and necessary help, problems would arise with the legitimisation of this state power (executive power). For this reason, structures should remain in place for possible cases of hardship and possible public traffic, but ideally they should be optimised in the sense of the modulation described above.

The digital transformation can only succeed if it is accepted by both the employees within the administration and the citizens. Here, there would be a danger that digitisation would not be perceived as support but as a burden. And public authorities in rural areas have so far provided secure and relatively well-paid jobs; a reduction in presence could lead to the fear of jobs being lost. It is therefore imperative that decisions be transparent and comprehensible. Changes must be actively and inclusively accompanied politically. After all, the administration must ultimately provide for the citizens of the state and acts on behalf of the people.

\section{Conclusion}

The organisational design of the digital transformation of its authorities ultimately remains the task of the state and is prioritised and pursued very differently with regard to the scope, intensity and speed of changes. In any case, there is room for manoeuvre in the structural and procedural organisation of the tax administration, which forms the starting point for this work. Agile principles could enable the administration to better respond to future challenges such as cross-border and international circumstances, complex corporate structures, taxation of digital business models, etc. As an answer to RQ1, with structural adjustments, a digital taxation process and automation-friendly tax laws, as well as the creation of a digital culture and understanding, the necessary agility can be increased. It was shown that there is an area of tension between providing services of general interest to citizens and, on the other hand, efficiency and cost savings. It is not only about the acceptance of digital solutions, but also the acceptance of no longer having a personal contact nearby in case of doubt. Even if hardly anyone uses it, citizens know they could. 
Concerning RQ2, the potential for reducing the number of authorities by streamlining structures could be shown by analysing the area and number of inhabitants, using Germany as an example. It can also be transferred to other countries. At the same time, a possibility for adaptation was shown. In addition, limits for this streamlining initiative were shown. The figure calculated for reducing the number of tax offices is only a theoretical reduction, but the local particularities must be taken into account in the implementation, which was not done here in the theoretical consideration. The results should therefore be relativised accordingly during implementation.

This calculation model could also be applied to other European countries and is not only restricted to Germany. However, the ratios calculated here for RQ2 are not valid everywhere and should be adapted and proofed. Collecting data from other countries and applying the model to that data and then comparing it with the data presented here would require considerable effort and must therefore be part of another research project in the future.

Within this framework, it was not possible to investigate the negative effects of telework and leadership and the associated change in work culture or the impact on people's perceptions of care in rural areas. This should be the subject of further research to better assess the practicality of the model presented here. In order to be able to take appropriate follow-up measures, it is advisable to evaluate the approaches described here after their implementation by the tax administrations. The change processes described here can also have a negative impact if they are not accompanied appropriately. The framework conditions necessary for this have only been addressed in rudimentary form and require further investigation.

\section{References}

Berg, A. 2021. 'Ein Jahr Corona: Wie hat die Pandemie unseren Alltag digitalisiert?' https://www.bitkom.org/sites/default/files/2021-03/bitkomcharts-ein-jahr-corona-10-03-2021_final.pdf.

Bundesministerium für Wirtschaft und Energie. 2021. 'Digitalisierung in Deutschland - Lehren aus der Corona-Krise.' https://www.bmwi.de/ Redaktion/DE/Publikationen/Ministerium/Veroeffentlichung -Wissenschaftlicher-Beirat/gutachten-digitalisierung-in-deutschland .pdf?_blob=publicationFile\&v $=4$.

Deutscher Bundestag. 2020. Drucksache 19/24339. https://dserver .bundestag.de/btd/19/243/1924339.pdf. 
Freistaat Sachsen. 2021. 'Ergebnisse der Bürgerbefragung der Finanzämter 2019/2020.' https://buergerbeteiligung.sachsen.de/portal/download/ datei/1355692_o/200409+Bürgerbefragung+Ergebnisse+TL.pdf.

Hermann, D., K. Hünecke, and A. Rohrberg. 2012. Führung auf DistanzMit virtuellen Teams zum Erfolg. 2nd ed. Wiesbaden: Springer Gabler. Hesse, J. J., A. Götz, and S. Schubert. 2007. Reform der Hoheitsverwaltung: Das Beispiel der Finanzverwaltung in Baden-Württemberg. BadenBaden: NomosVerlagsgesellschaft.

Kulicke, F. 2020. 'Digitalisierung der Daseinsvorsorge in Mittelzentren: Status quo und Entwicklungsperspektiven in Rheinland-Pfalz.' Trierer Arbeitsberichte zur Stadt- und Wirtschaftsgeographie, University of Trier. https://www.uni-trier.de/fileadmin/fb6/prof/KUR/

Digitalisierung_der_Daseinsvorsorge_in_MZ_Franziska_Kulicke.pdf.

Lenz, J., A. Witte, and S. Saebisch. 2021. 'Free The Economy. Ansätze zur Bewältigung der Corona-Wirtschaftskrise.' Policy Paper, FriedrichNaumann-Stiftung für die Freiheit, Potsdam. https://shop.freiheit.org /\#!/Publikation/1056.

Lévesque, V. 2018. 'Agile Arbeitsformen im nicht-agilen Umfeld.' In Agile Verwaltung - Wie der Öffentliche Dienst aus der Gegenwart die Zukunft entwickeln kann, edited by M. Bartonitz, V. Lévesque, T. Michl, W. Steinbrecher, C. Vonhof, and L. Wagner, 163-67. Wiesbaden: Springer Gabler.

Lévesque, V., and T. Michl. 2018. 'Agilität - die Zukunft der Öffentlichen Verwaltung?' In Agile Verwaltung - Wie der Öffentliche Dienst aus der Gegenwart die Zukunft entwickeln kann, edited by M. Bartonitz, V. Lévesque, T. Michl, W. Steinbrecher, C. Vonhof, and L. Wagner, 41-51. Wiesbaden: Springer Gabler.

Lévesque, V., and C. Vonhof. 2018. 'Komplexität, vu KA und andere Schlagworte - was verbirgt sich dahinter?' In Agile Verwaltung - Wie der Öffentliche Dienst aus der Gegenwart die Zukunft entwickeln kann, edited by M. Bartonitz, V. Lévesque, T. Michl, W. Steinbrecher, C. Vonhof, and L. Wagner, 15-22. Wiesbaden: Springer Gabler.

Lohmann, B. 2018. 'Die digitale Verwaltung.' In Digitalisierung in Recht, Politik und Verwaltung, edited by H. Hill, D. Kugelmann, and M. Martini, 9-18. Baden-Baden: Nomos.

Michl, T., and W. Steinbrecher. 2018. 'Wozu kann unsere Gesellschaft eine »agile Verwaltung « brauchen?' In Agile Verwaltung - Wie der Öffentliche Dienst aus der Gegenwart die Zukunft entwickeln kann, edited by M. Bartonitz, V. Lévesque, T. Michl, W. Steinbrecher, C. Vonhof, and L. Wagner, 23-40. Wiesbaden: Springer Gabler.

Peuthert, B., and D. S. Schaebs. Forthcoming. 'Paradigmenwechsel in der Aus- und Fortbildung von Steuerbeamten - Zeitgemäße Anforderun- 
gen, konsekutive Modularisierung und Konzepte zur Vermittlung digitaler Kompetenzen' beck.digitax.

Peuthert, B., C. Schmidt, R. Müller, and D. S. Schaebs. 2021. 'Perspektiven für den künftigen Umgang und die Nutzung von digitalen Daten im Besteuerungsverfahren. beck.digitax (4): 236-42.

Schaebs, D. S. 2020. 'Germany - Tail Light Position in Digitisation: An Analysis of a Decentralised Tax Administration Based on the Digital European Society Index.' Management 15 (4): 309-23.

—. Forthcoming. 'Contemporary e-Government for Smart Tax Authorities.' Electronic Government - an International Journal. https:// www.doi.org/10.1504/EG.2022.10039687.

Statistisches Bundesamt. 2019. 'Lebenslagenbefragung 2019 - Bürgerinnen und Bürger.' https://www.amtlich-einfach.de/SharedDocs/Downloads /Erebnisse_Buerger_2019.pdf?_blob=publicationFile\&v=2.

Steuck, A. 2019. Mit einer schwarmintelligenten Verwaltung agil und stabil in die Zukunft - Eine empirische Untersuchung am Beispiel der Bundesverwaltung. Wiesbaden: Springer Gabler.

Vonhof, C. 2018. 'Bibliotheken und Agilität - Welten begegnen sich?' In Agile Verwaltung - Wie der Öffentliche Dienst aus der Gegenwart die Zukunft entwickeln kann, edited by M. Bartonitz, V. Lévesque, T. Michl, W. Steinbrecher, C. Vonhof, and L. Wagner, 169-83. Wiesbaden: Springer Gabler.

Zirkler, M., N. Scheidegger, and A. I. Bargetzi. 2020. Führung auf Distanz - Eine Untersuchung zur Distanzführung während des coronabedingten Lockdowns 2020 an der ZHAW. Zürich: Zürcher Fachhochschule. 